ANL-5966

Metallurgy and Ceramics

(TID-4500, 14th Ed.)

AEC Research and

Development Report

\author{
ARGONNE NATIONAL LABORATORY \\ P. O. Box 299 \\ Lemont, Illinois
}

\begin{abstract}
RECRYSTALLIZATION OF HEAVILY COLD-ROLLED URANIUM SHEET
by

W. R. Yario and L. T. Lloyd
\end{abstract}

Metallurgy Division

Partial Report - Metallurgy Program 4.1.5

Portions of the material in this report have appeared in the following Metallurgy Division Quarterly Reports:

\begin{tabular}{lll} 
Number & Page & \multicolumn{1}{c}{ Date } \\
ANL-5623 & $42-52$ & November 1956 \\
ANL-5643 & $31-35$ & March 1957 \\
ANL-5709 & $32-36$ & December 1956 \\
ANL-5717 & $51-55$ & March 1957 \\
ANL-5790 & $40-43$ & July 1958 \\
ANL-5797 & $39-41$ & October 1958 \\
ANL-5837 & Section V.1.c &
\end{tabular}

May 1959

Operated by The University of Chicago

under

Contract W-31-109-eng-38 


\section{DISCLAIMER}

This report was prepared as an account of work sponsored by an agency of the United States Government. Neither the United States Government nor any agency Thereof, nor any of their employees, makes any warranty, express or implied, or assumes any legal liability or responsibility for the accuracy, completeness, or usefulness of any information, apparatus, product, or process disclosed, or represents that its use would not infringe privately owned rights. Reference herein to any specific commercial product, process, or service by trade name, trademark, manufacturer, or otherwise does not necessarily constitute or imply its endorsement, recommendation, or favoring by the United States Government or any agency thereof. The views and opinions of authors expressed herein do not necessarily state or reflect those of the United States Government or any agency thereof. 


\section{DISCLAIMER}

Portions of this document may be illegible in electronic image products. Images are produced from the best available original document. 
TABLE OF CONTENTS

Page

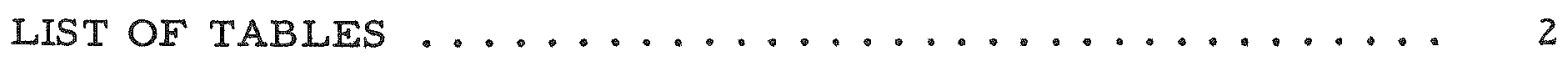

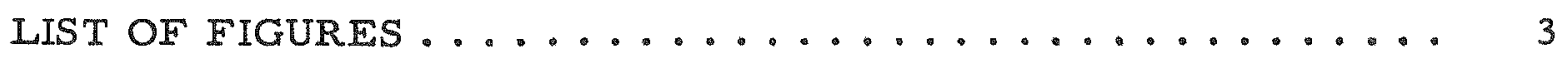

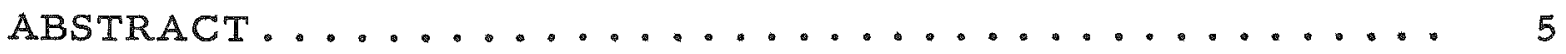

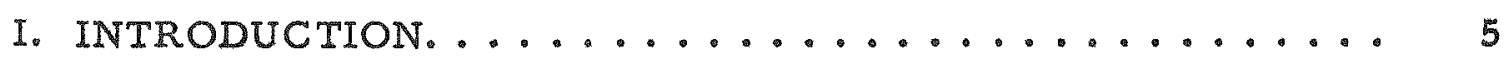

II. MATERIALS AND EXPERIMENTAL TECHNIQUES . . . . 6

A. Materials and Fabrication ................ 6

B. Experimental Techniques................. 9

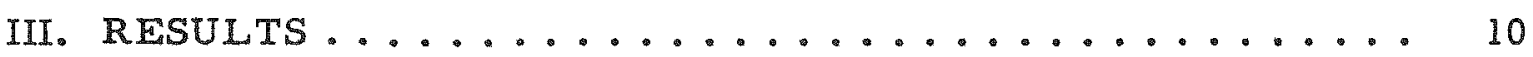

A. Sample Fabrications........................ 10

B. Dilatometric and Volume Percent Recrystallization

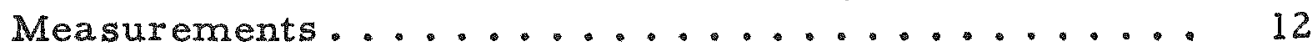

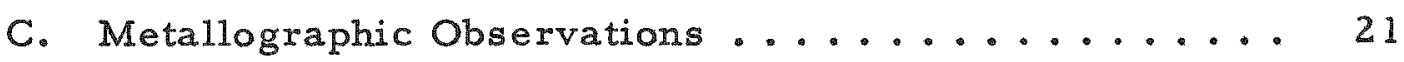

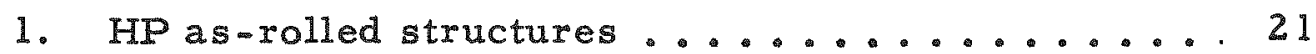

2. Structures of HP specimens annealed 15 hours at

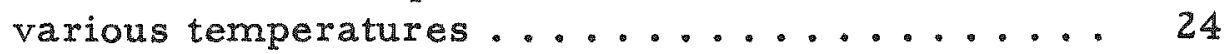

3. Structures of HP specimens annealed various

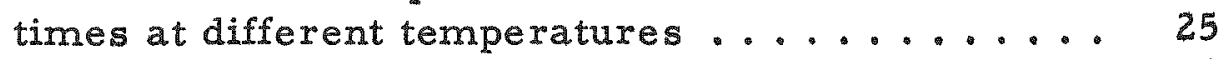

4. Structures of sheet $\mathrm{N}$ specimens........... 33

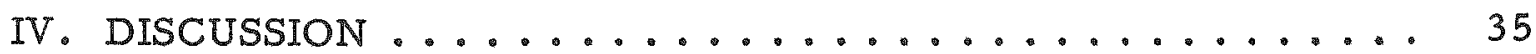

A. Effect of Annealing upon Preferred Orientation

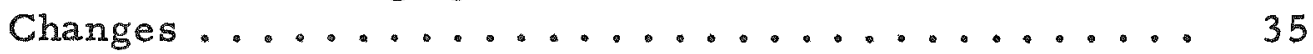

B. Effect of Annealing upon Microstructure......... 37

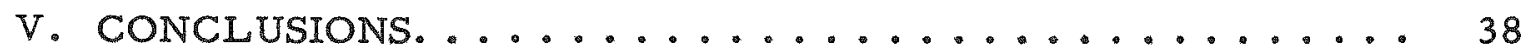

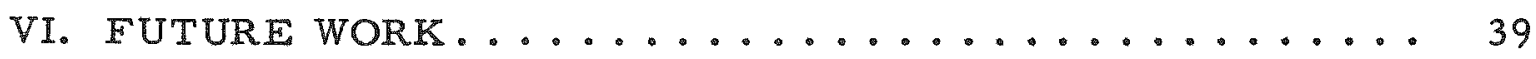

VII. ACKNOWLEDGMENT ..................... 40

VIII. REFERENCES ......................440 
No.

I. Chemical Analyses of Materials ............... 6

II. Rolling Conditions Employed for Preparation of Samples...

III. Volume Percent Recrystallization and Thermal Expansion Data for Heavily Cold-Rolled Uranium Specimens Given

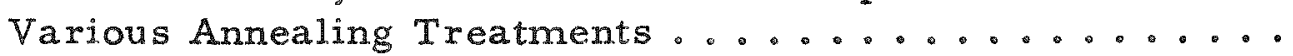

IV. Volume Percent Recrystallization and Change in Mean Expansion Coefficient for Specimens Given Second and Third Annealing Treatments. ...............

V. Effect of Annealing Treatment upon Amount of Speckled-

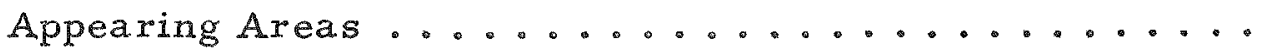

VI. Average Grain Size, Volume Percent Recrystallization and Change in Mean Expansion Coefficient for Selected

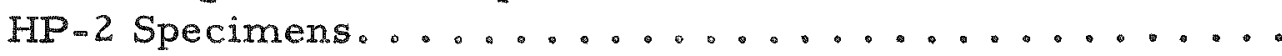




\section{LIST OF FIGURES}

No.

Title

Page

1. Sequence of Operations Employed in Fabricating

Sheet Samples.....................

2. Appearance of Samples B555 and A50 after Rolling to

$80 \%$ Reduction in Thickness at Room Temperature......

3. Volume Percent Recrystallization of HP-1 Specimens

Annealed for a Constant Time Interval of 15 Hours

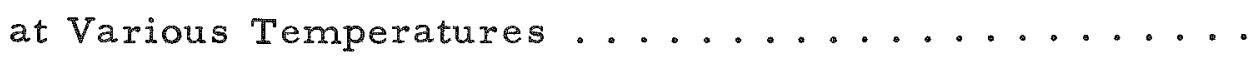

4. Dilatation Curves of Longitudinal HP-1 Specimens

Annealed for a Constant Time Interval of 15 Hours at

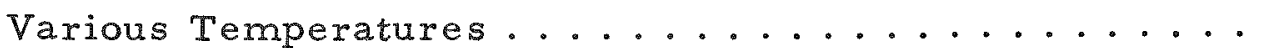

5. Dilatation Curves of Transverse HP-1 Specimens

Annealed for a Constant Time Interval of 15 Hours at

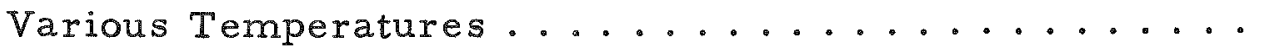

6. HP- 1 Specimens Annealed 15 Hours at $360^{\circ} \mathrm{C}$, Tested

in the Dilatometer and Macroetched ............

7. Change of Mean Expansion Coefficient between $200^{\circ}$ and $300^{\circ} \mathrm{C}$, over that Obtained from an As-Rolled Specimen, as a Function of Volume Percent Recrystallization for Transverse HP-1 Specimens Annealed 15 Hours at Various Temperatures .........

8. Volume Percent Recrystallization of Specimens from the Three Material Fabrications as a Function of Annealing Time at $360^{\circ} \mathrm{C} \ldots \ldots \ldots$

9. Volume Percent Recrystallization of Specimeng from the Three Material Fabrications as a Function of Annealing Time at $400^{\circ} \mathrm{C} \ldots \ldots \ldots \ldots$

10. Change of Mean Expansion Coefficient between $200^{\circ}$ and $300^{\circ} \mathrm{C}$, over that Obtained from an As-Rolled Specimen, as a Function of Volume Percent Recrystallization for Transverse HP-2 Specimens Annealed for Varying Periods of Time at Various

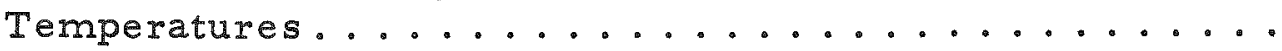




\section{LIST OF FIGURES}

No.

Title

Page

11. Change of Mean Expansion Coefficient Between $200^{\circ}$ and $300^{\circ} \mathrm{C}$, over that Obtained from an As-rolled Specimen, as a Function of Volume Percent Recrystallization for Transverse Sheet $N$ Specimens Annealed for Varying Periods of Time at Various Temperatures...............

12. Microstructures of As-rolled HP-1 Specimens Showing Types of Deformed Structure Zones.............

13. Microstructures of HP-1 Specimens Annealed 15 Hours

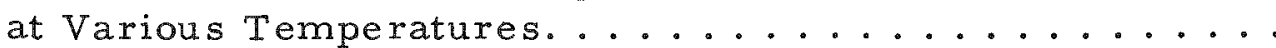

14. HP-1 Specimens Annealed at $360^{\circ} \mathrm{C}$ for Varying Periods

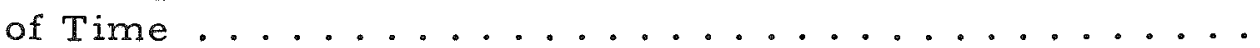

15. The Change in Appearance of Very Fine Recrystallized

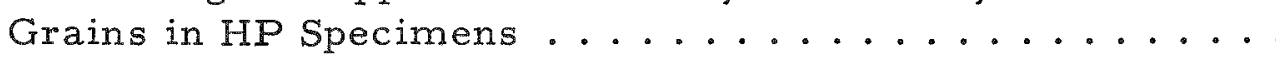

16. Recrystallization Behavior of Lightly Deformed Areas

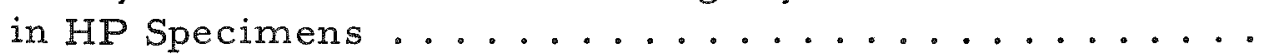

17. Recrystallization Behavior of a Lightly Deformed Area in a HP Specimen Annealed 15 Hours at $380^{\circ} \mathrm{C} \ldots \ldots$

18. Grain Coarsening in a HP-2 Specimen Annealed 200 Hours at $320^{\circ} \mathrm{C}$ and Reannealed 48 Hours at $650^{\circ} \mathrm{C} \ldots \ldots \ldots$

19. Microstructures of As-rolled Sheet $\mathrm{N}$ Specimens......

20. Microstructures of Annealed Sheet $N$ Specimens ....... 


\title{
RECRYSTALLIZATION OF HEAVILY COLD-ROLLED URANIUM SHEET
}

\author{
W. R. Yario and L. T. Lloyd
}

\begin{abstract}
Changes in mean expansion coefficients upon annealing uranium sheet that had been rolled to $80 \%$ reduction in thickness at room temperature indicated that three different preferred orientations could be developed upon recrystallization. One preferred orientation, which is essentially the same as that of the as-rolled material, resulted from annealing for long times at $360^{\circ} \mathrm{C}$ or at a lower temperature; a second type was created by annealing for moderate times between $400^{\circ}$ and $600^{\circ} \mathrm{C}$; and the third accompanied grain coarsening at $650^{\circ} \mathrm{C}$. The microstructures of the as-rolled and annealed specimens were extremely heterogeneous because of the large grain size present prior to final fabrication at room temperature. The as-rolled structures consisted of heavily deformed areas and smaller quantities of lightly de. formed material. The annealing of the former was characterized by initial creation of very fine recrystallized grains which were absorbed later by discontinuous growth of larger grains. Lightly deformed areas, upon annealing, first exhibited recovery by polygonization and then underwent normal recrystallization.
\end{abstract}

\section{INTRODUCTION}

The recrystallization of cold deformed, polycrystalline alpha uranium has been the subject of numerous investigations; unique among these is the work of Cabane and Petit.(1) In their study of uranium sheet, rolled to $80 \%$ reduction in thickness at room temperature, the authors reported recrystallization at temperatures between $320^{\circ}$ and $420^{\circ} \mathrm{C}$ without the occurrence of a preferred orientation change. At temperatures just above $420^{\circ} \mathrm{C}$ they found that a second recrystallization occurred; this was accompanied by a change in preferred orientation. Presumably the latter was not the same as the normal "secondary recrystallization" that would occur at temperatures near the upper limit of stability of the alpha range.

Because the recrystallization of deformed polycrystalline uranium without a preferred orientation change had not been reported previously, a program has been undertaken to verify this phenomenon. The present work 
was performed on high-purity uranium, for it was felt that the purity of the metal might be a significant factor. The techniques utilized were slightly different from those of Cabane and Petit. To verify the validity of the pres ent methods, arrangements were made through Cabane to exchange test materials. A portion of the same ingot of high-purity uranium investigated in the present work was sent to the Commissairiat á l'Energie Atomique Centre d'Etudes Nucleaires de Saclay and, in return, Argonne National Laboratory received some of the material used in the original work of Cabane and Petit.

\section{MATERIALS AND EXPERIMENTAL TECHNIQUES}

A. Materials and Fabrication

Chemical analyses of the high-purity uranium ingot $\mathrm{HPX}-16$ and the sheet $\mathrm{N}$ sample furnished by Cabane are given in Table I. In both metals the primary impurities were the lighter elements: carbon, nitrogen and oxygen.

TABLE I

Chemical Analyses of Materials

\begin{tabular}{|l|c|c|c|}
\hline \multirow{2}{*}{ Element* } & \multicolumn{3}{|c|}{ Composition (parts per million by weight) } \\
\cline { 2 - 4 } & $\begin{array}{c}\text { High-Purity } \\
\text { Uranium Ingot } \\
\text { HPX-16 (top) }\end{array}$ & $\begin{array}{c}\text { Analyses Reported } \\
\text { by French }\end{array}$ & $\begin{array}{c}\text { Analyses Determined } \\
\text { at ANL }\end{array}$ \\
\cline { 3 - 4 } & & $-* * *$ & 31 \\
$\mathrm{C}$ & 34,38 & - & 67 \\
$\mathrm{~N}$ & L10 & - & 27 \\
$\mathrm{O}$ & 23,24 & - & 10 \\
$\mathrm{Al}$ & 7 & 28 & 10 \\
$\mathrm{Cu}$ & 2 & 36 & 40 \\
$\mathrm{Fe}$ & 4 & - & 2 \\
$\mathrm{Mg}$ & 1 & 5 & 3 \\
$\mathrm{Mn}$ & L1** & 6 & 5 \\
$\mathrm{Ni}$ & L5 & 100 & 20 \\
$\mathrm{Si}$ & 10 & & \\
\hline
\end{tabular}

*All other elements are below the limits of spectrochemical detection for analyses performed at ANL

** L indicates that the material contains less than the indicated quantity of the particular elements.

*** Indicates that analyses were not reported. 
The French sheet $\mathrm{N}$ sample was prepared from biscuit produced by calcium reduction of $\mathrm{UF}_{4}$. A suitable portion was given a breakdown roll at $600^{\circ} \mathrm{C}$ and then heat treated in a salt bath for one-half hour at a temperature within the beta phase $\left(720^{\circ} \mathrm{C}\right)$, followed by cooling in air to room temperature. Subsequent to this, the sample was annealed for 5 hours at $500^{\circ} \mathrm{C}$ and furnace cooled. Finally, it was rolled to $80 \%$ reduction in thickness at room temperature.

Four different samples were fabricated at ANL. Two of these, B555 and A50, served to determine suitable room temperature-rolling procedures for preparing the two portions of the high-purity uranium ingot HPX-16, subsequently referred to as HP-1 and HP-2. In the preparation of these samples, the procedure followed by Cabane and Petit was duplicated as nearly as possible with the exceptions that the heat treatments in the beta phase and at $500^{\circ} \mathrm{C}$ were carried out in an evacuated container rather than in a liquid salt bath. These deviations from the procedure were adopted in order to reduce contamination of the samples.

The sequence of operations in the preparation of the samples is depicted in Figure 1. The as-cast structure of the round ingot was

Figure 1. Sequence of Operations Employed in Fabricating Sheet Samples. Dimensions refer to preparation of first portion of high-purity ingot $(\mathrm{HP}-\mathrm{I})$.

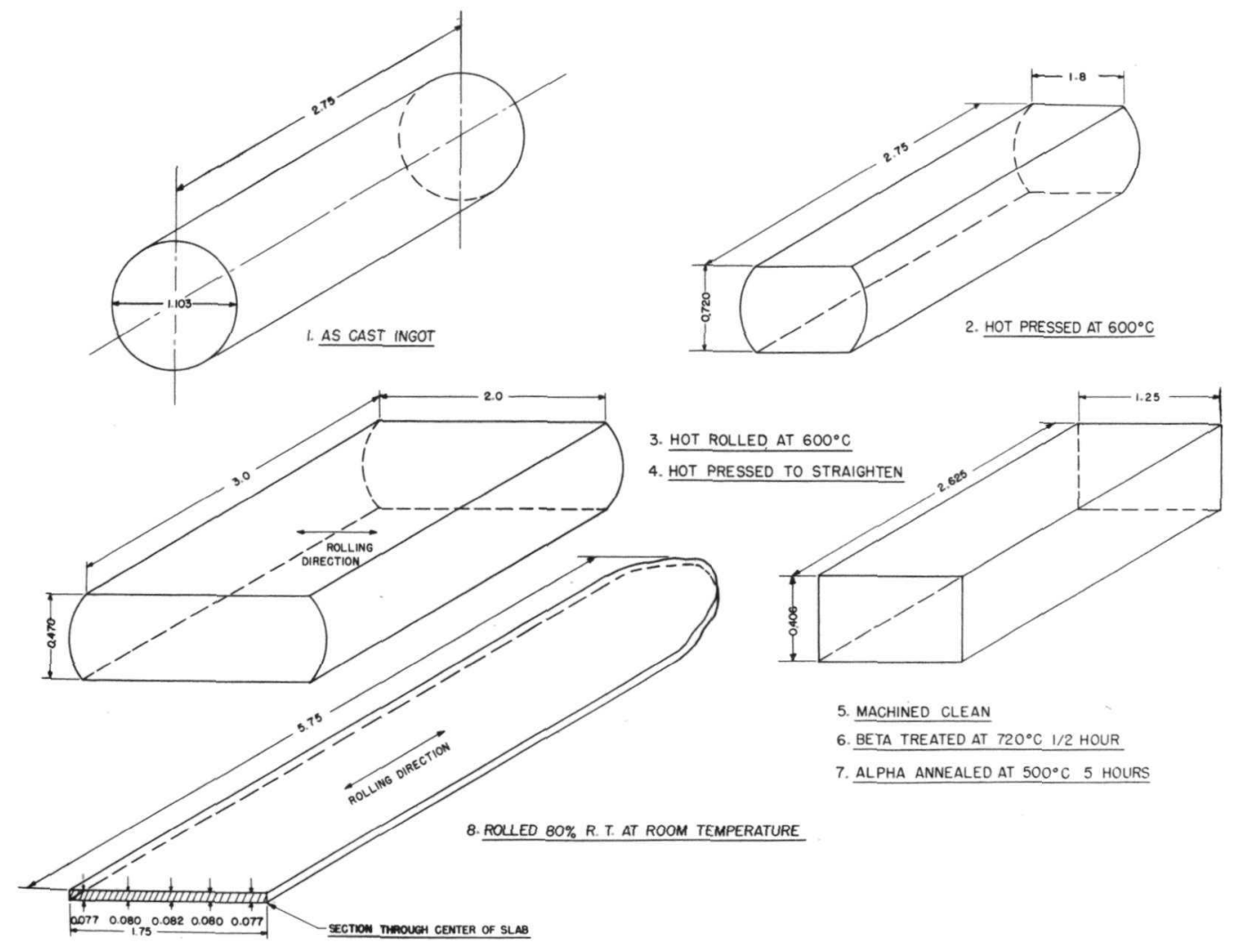


broken up by fabrication at $600^{\circ} \mathrm{C}$, using lead as a preheat bath. Flat surfaces were developed parallel to the cylindrical axis of the round by pressing at $600^{\circ} \mathrm{C}$. The piece was then rolled at the same temperature in a direction perpendicular to the original cylindrical axis to a thickness of approximately one half of the original diameter. The sample was then flattened by pressing at $600^{\circ} \mathrm{C}$ and subsequently machined at room temperature into a regular geometrical shape and to remove any surface contamination resulting from the $600^{\circ} \mathrm{C}$ treatments. The resulting slab was placed in a container which was evacuated and submerged in a lead bath at $720^{\circ} \mathrm{C}$. After holding for one-half hour at this temperature, the sample was cooled in air to room temperature. This treatment produced a nearly random orientation. The container was again evacuated and placed in a lead bath at $500^{\circ} \mathrm{C}$ where it was held for five hours and then furnace cooled to room temperature. The purpose of this treatment was to reduce the internal stresses within the slab.

After the above preparation, the samples were rolled to approximately $80 \%$ reduction in thickness at room temperature in a direction parallel to the original cylindrical axis. The rolling conditions of these fabrications and the rollings at $600^{\circ} \mathrm{C}$ for each sample are given in Table II. For rolling at room temperature, the principal variables were the sizes of the rolls and the accompanying reductions per pass. In all instances care was taken to make sure that the temperature of the sample did not rise sensibly above room temperature.

TABLE II

Rolling Conditions Employed for Preparation of Samples

\begin{tabular}{|l|c|c|c|c|c|c|c|}
\hline & \multicolumn{3}{|c|}{$600^{\circ} \mathrm{C}$ Rolling } & \multicolumn{3}{c|}{ Room-Temperature Rolling* } \\
\cline { 2 - 8 } $\begin{array}{c}\text { Sample } \\
\text { Number }\end{array}$ & $\begin{array}{c}\text { Roll } \\
\text { Diameter } \\
\text { (in.) }\end{array}$ & $\begin{array}{c}\text { Number } \\
\text { of } \\
\text { Passes }\end{array}$ & $\begin{array}{c}\text { Total } \\
\text { Reduction } \\
(\%)\end{array}$ & $\begin{array}{c}\text { Roll } \\
\text { Diameter } \\
(\text { in.) }\end{array}$ & $\begin{array}{c}\text { Average } \\
\text { Reduction } \\
\text { per Pass } \\
(\%)\end{array}$ & $\begin{array}{c}\text { Number } \\
\text { of } \\
\text { Passes }\end{array}$ & $\begin{array}{c}\text { Total } \\
\text { Reduction } \\
(\%)\end{array}$ \\
\hline B 555 & 5 & 11 & 29 & 5 & 0.5 & 200 & 80 \\
A 50 & $* *$ & - & - & 9 & 8.1 & 19 & 80 \\
HPX-16-1 & 5 & 22 & 34 & 17 & 9.0 & 17 & 80 \\
HPX-16-2 & 5 & 16 & 35 & 9 & 9.7 & 16 & 81 \\
\hline
\end{tabular}

* The lead end of the sample was reversed between each pass.

**Sample A50 had been rolled at $600^{\circ} \mathrm{C}$ followed by $50 \%$ reduction in thickness at $300^{\circ} \mathrm{C}$ prior to the heat treatment in the beta phase employed in the present work. 
B. Experimental Techniques:

Two types of specimens were prepared from the HP fabrications; these were metallographic specimens of random size, and dilatometric specimens 1,000 in. in length, $0.200 \mathrm{in.} \mathrm{in} \mathrm{width,} \mathrm{and} \mathrm{approximately} 0.080 \mathrm{in}$. in thickness. Each of the latter was prepared with the long dimension either parallel (longitudinal specimens) or perpendicular (transverse specimens) to the rolling direction and lying in the rolling plane. All specimens were cut from the sheet samples with an abrasive cut-off wheel and ground to final dimensions; particular care was taken so as not to overheat during these operations.

All heat treatments were performed in molten baths of either lead or bismuth-lead eutectic. Specimens annealed for short periods of time (that is, up to 60 minutes) were coated with silicone grease and immersed directly in the molten metal. All others were cleaned by electropolishing; they were then wrapped in tantalum foil and placed in a stainless steel container which was subsequently evacuated to a pressure of approximately $1 \times 10^{-5} \mathrm{~mm}$ of mercury and immersed in the molten bath for heat treatment. In all cases the specimens were air-cooled to room temperature subsequent to the anneals.

Expansion curves were obtained with a quartz differential dilatometer.(2) The rate of heating in all tests was approximately $1^{\circ} \mathrm{C}$ per minute, while the cooling rate was uncontrolled. Only data obtained on heating were measured because of errors that could be introduced if the quartz push rod did not follow the specimen upon cooling. Dilatation curves of as-rolled specimens were measured up to $315^{\circ} \mathrm{C}$, and the annealed specimens were run to $10^{\circ} \mathrm{C}$ below their temperatures of heat treatment. The measure of dilatometric behavior finally adopted was the mean expansion coefficient between $200^{\circ}$ and $300^{\circ} \mathrm{C}$. The upper temperature was dictated by the behavior of the as-rolled specimens and the minimum annealing temperature of $320^{\circ} \mathrm{C}$. The lower temperature was chosen in an effort to reduce errors due to improper seating of the specimen. All data for the determination of the thermal expansion coefficients were corrected for the expansion of quartz.

Metallographic observations were obtained from specimens prepared specifically for that purpose and from many dilatometer specimens after testing. These were prepared by grinding on water-lubricated, rotating, silicon carbide papers up through $600 \mathrm{mesh}$, followed by successive mechanical polishing with diamond abrasives of 6,3 and 1 -micron sizes. The specimens were then electropolished in a solution containing 5 parts orthophosphoric acid, 5 parts ethylene glycol and 8 parts ethyl alcohol at a current density of 30 milliampers per square centimeter for 5 to 10 minutes. All observations, measurements and photographs were obtained with polarized light illumination of a Bausch and Lomb research 
Metallograph. In cases where photographs were to be taken at high magnification (near 1000X) particular care was necessaryduring the surface preparation to prevent removal of inclusions. If these were torn out, the depressions would scatter the polarized light beam and much of the true structure would be obliterated during the long exposure times required for photographing. For this particular application the diamond abrasive polishing was performed by hand on lens tissue laps rather than using rotating cloth laps. For reasonable contrast at high magnifications up to $1350 \mathrm{X}$, the $80 \mathrm{X}$ APO, $1.40 \mathrm{~N} . \mathrm{A}$. objective in conjunction with the $5 \mathrm{X}$ hyperplane eyepiece proved to be the best combination.

Measurements of the volume percent of recrystallization were made with a Bausch and Lomb grain-size eyepiece. By counting the number of squares covering recrystallized material in a specific field and dividing this by the total number of squares, the fraction of the material recrystallized was determined.(3) Fifty random areas were measured for each specimen so as to insure statistical sampling. Grain size measurements were determined by a line intercept method.(3) In each case the length of line for approximately 500 grains was measured; this, divided by the number of grains, yielded the average grain diameter. The measurements of. hardness of the as-rolled material were made with a Bergsman microhardness tester, using a load of 100 grams applied for 15 seconds.

\section{RESULTS}

\section{A. Sample Fabrications}

The results of the preliminary room-temperature fabrications of samples B555 and A50 are shown pictorially in Figure 2. Edge and surface cracks appeared in sample B555 after a reduction in thickness of only $12 \%$. The sizes and number of these increased with further reductions, and after $45 \%$ reduction the edge cracks had grown completely across the slab. After $80 \%$ reduction the piece was extremely weak and a small bend. was sufficient to break it. Metallographic observations showed that cracks were present within the body of the sheet as well as on the surface and that the grains near the rolling surfaces were considerably more deformed than those in the center. Sample A50 showed a few small surface cracks after $25 \%$ reduction in thickness; however, the sizes and quantity of these did not increase appreciably throughout the remainder of the rolling. Edge cracking appeared after $50 \%$ reduction but did not grow appreciably across the sample. Metallographic examination did not show the presence of cracks within the body of the sheet, and the deformation was more uniform across its thickness. 
Figure 2. Appearance of Samples B555 and A50 After Rolling to 80\% Reduction in Thickness at Room Temperature.

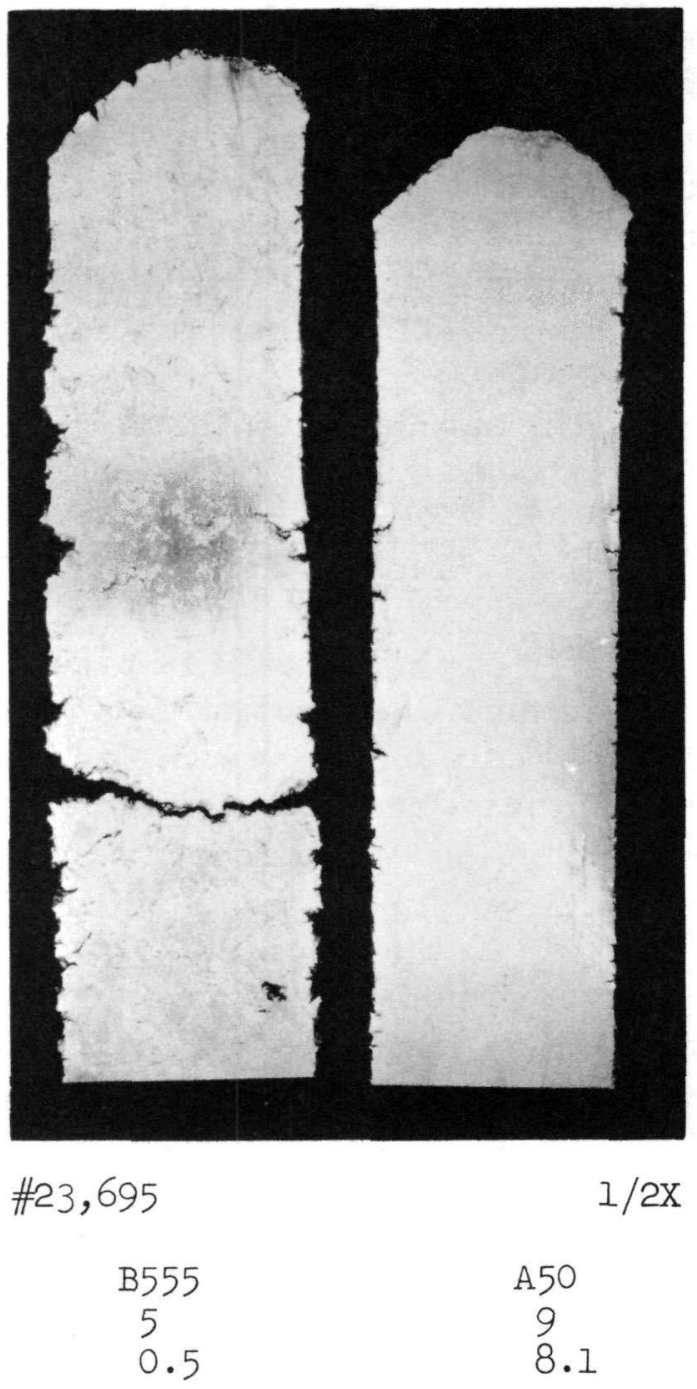

Sample

Roll Diameter (in.)

Average \% Reduction per Pass

It is quite obvious that the rolls of smaller diameter did not yield a suitable sample. The improvement of sample A50 over B555 undoubtedly was due to the use of rolls of larger diameter and to heavier reductions. Such conditions result in more uniform deformation across the thickness of the slab and reduce the excessive surface work hardening.

Because of the improved appearance of sample A50 over that of sample B555, the first portion of ingot HPX-16 (HP-1) was rolled at room temperature on a mill of still larger diameter (17 in.). Edge cracks appeared in the early stages of rolling; however, they never grew more than $1 / 8$ in. across the surface. A few small surface cracks developed; however these did not interfere with the usefulness of the material. The interior of the sample did not show any cracks. A detailed description of the microstructure will be given below.

As this study progressed it became necessary to obtain additional specimens of the high-purity material. At that time the $17 \mathrm{in}$. diameter mill was unavailable and the second portion of HPX-16 (HP-2) 
was fabricated on the 9 in. mill. The finished product was quite satis factory; however, it had larger edge cracks than did the A50 or HP-1 samples. The smaller roll diameter used for HP-2 probably accounts for the greater edge cracking than in HP-1. On the other hand, the higher purity and accompanying larger grain size prior to final rolling explains the larger edge cracking of $\mathrm{HP}-2$ in comparison to that of sample A50. The as-rolled microstructure of HP-2 was very similar to that observed for HP-1. Some differences in the behavior of the two materials did occur upon annealing; these will be discussed below.

\section{B. Dilatometric and Volume Percent Recrystallization Measurements}

In Table III is recorded the experimentally determined mean coefficients of expansion between $200^{\circ}$ and $300^{\circ} \mathrm{C}$, together with corres ponding data on the volume percent of recrystallization. Some of the specimens were used for metallographic observations only; therefore, no expansion coefficients are reported for these.

Due to the laborious nature of the measurements of volume percent of recrystallization, values were not determined from each of the dilatometric specimens. Sufficient measurements were made, however, so that the percent recrystallization was known for each different annealing treatment. In cases where more than one determination of percent recrystallization were made for a particular fabrication and heat treatment, the values agreed well; for example, HP-1 specimens annealed for 15 hours at $400^{\circ} \mathrm{C}$ gave percent recrystallizations of $93,94,96,97$ and $98 \%$. Meas urements of the percent recrystallization subsequent to dilatation testing did not give values significantly different from that measured for a specimen in the annealed state; for example, a HP 1 specimen annealed for 15 hours at $360^{\circ} \mathrm{C}$ yielded $29 \%$ recrystallization and others annealed and dilatation tested yielded 26 and $30 \%$ recrystallizations.

The curve of volume percent of recrystallization of $\mathrm{HP}-1$ specimens annealed for a constant period of 15 hours at various temperatures is shown in Figure 3. It has a normal. "S" shape with a point of inflection at approximately $370^{\circ} \mathrm{C}$. Figures 4 and 5 show typical expansion curves of these specimens, obtained from longitudinal and transverse directions, respectively. Both sets of curves indicate a shift of expansion coefficient as the annealing temperature is increased and a significant change for specimens annealed at $400^{\circ} \mathrm{C}$ or higher. For the longitudinal specimens, the shift in expansion coefficient was somewhat erratic, but, in general, it decreased as the annealing temperature increased. The change in expansion coefficient as a function of annealing temperature for the transverse specimens was more consistent; an increase in the annealing temperature resulted in an increase in expansion coefficient. The probable reason for the erratic behavior for the expansion of the longitudinal specimens over that of the transverse specimens is illustrated in 
TABLE III

Volume Percent Recrystallization and Thermal Fxpansion Data fo

\begin{tabular}{|c|c|c|c|c|c|c|c|c|c|c|c|c|c|c|c|c|c|}
\hline \multicolumn{2}{|c|}{ Annealing Treatment } & \multicolumn{8}{|c|}{ First Fabrication of High-Purity Uranium-HP-1 } & \multicolumn{4}{|c|}{$\begin{array}{l}\text { Second Fabrication of High-Purity } \\
\text { Uranium-HP-2 }\end{array}$} & \multicolumn{4}{|c|}{ French Uranium - Sheet $\mathrm{N}$} \\
\hline \multirow{3}{*}{$\begin{array}{c}\text { Temper- } \\
\text { ature } \\
\left({ }^{\circ} \mathrm{C}\right)\end{array}$} & \multirow{3}{*}{ Time } & \multicolumn{4}{|c|}{ Longitudinal Specimens } & \multicolumn{4}{|c|}{ Transverse Specimens } & \multicolumn{4}{|c|}{ Transverse Specimens } & \multicolumn{4}{|c|}{ Transverse Specimens } \\
\hline & & \multirow{2}{*}{$\begin{array}{c}\text { Specimen } \\
\text { Number }\end{array}$} & \multirow{2}{*}{$\begin{array}{c}\text { Volume } \\
\text { Percent } \\
\text { Recrys- } \\
\text { tallized* }\end{array}$} & \multicolumn{2}{|c|}{$\begin{array}{l}\text { Mean Expansion } \\
\text { Coefficient } \\
\text { between } \\
200^{\circ} \text { and } 300^{\circ} \mathrm{C} \\
\left(\times 10^{6} \text { per }{ }^{\circ} \mathrm{C}\right)\end{array}$} & \multirow{2}{*}{$\begin{array}{l}\text { Specimen } \\
\text { Number }\end{array}$} & \multirow{2}{*}{$\begin{array}{c}\text { Volume } \\
\text { Percent } \\
\text { Recrys- } \\
\text { tallized }\end{array}$} & \multicolumn{2}{|c|}{$\begin{array}{l}\text { Mean Expansion } \\
\text { Coefficient } \\
\text { between } \\
200^{\circ} \text { and } 300^{\circ} \mathrm{C} \\
\left(\times 10^{6} \text { per }{ }^{\circ} \mathrm{C}\right)\end{array}$} & \multirow{2}{*}{$\begin{array}{l}\text { Specimen } \\
\text { Number }\end{array}$} & \multirow{2}{*}{$\begin{array}{c}\text { Volume } \\
\text { Percent } \\
\text { Recrys- } \\
\text { tallized** }\end{array}$} & \multicolumn{2}{|c|}{$\begin{array}{l}\text { Wean Expansion } \\
\text { Coefficient } \\
\text { between } \\
200^{\circ} \text { and } 300^{\circ} \mathrm{C} \\
\left(\times 10^{6} \text { per }{ }^{\circ} \mathrm{C}\right)\end{array}$} & \multirow{2}{*}{$\begin{array}{l}\text { Specimen } \\
\text { Number }\end{array}$} & \multirow{2}{*}{$\begin{array}{c}\text { Volume } \\
\text { Percent } \\
\text { Rerys- } \\
\text { tallized }\end{array}$} & \multicolumn{2}{|c|}{$\begin{array}{l}\text { Mean Expansion } \\
\text { Coefficient } \\
\text { between } \\
200^{\circ} \text { and } 300^{\circ} \mathrm{C} \\
\left(\times 10^{6} \text { per }{ }^{\circ} \mathrm{C}\right)\end{array}$} \\
\hline & & & & Value & \begin{tabular}{|c|} 
Change \\
from \\
As-rolled \\
Value \\
\end{tabular} & & & Value & $\begin{array}{c}\text { Change } \\
\text { from } \\
\text { As-rolled } \\
\text { Value }\end{array}$ & & & Value & \begin{tabular}{|c|} 
Change \\
from \\
As-rolled \\
Value \\
\end{tabular} & & & Value & $\begin{array}{c}\text { Change } \\
\text { from } \\
\text { As-rolled } \\
\text { Value }\end{array}$ \\
\hline \multicolumn{2}{|c|}{ As Rolled } & 2 & 0 & 15.43 & 0.00 & 1 & 0 & 18.59 & 0.00 & ** & 0 & 19.73 & 0.00 & 17 & 0 & 19.81 & 0.00 \\
\hline 320 & $\begin{array}{rl}15 & \mathrm{hr} \\
200 \mathrm{hr} & \{ \\
400 \mathrm{hr} & \end{array}$ & 8 & $\cdots \cdots$ & 10.35 & -5.08 & 7 & 10 & 18.92 & 0.33 & $\begin{array}{r}5 \\
6 \\
28 \\
31 \\
\end{array}$ & $\begin{array}{c} \\
72 \\
- \\
75 \\
-\end{array}$ & $\begin{array}{l}20.16 \\
19.79 \\
18.69 \\
19.52 \\
\end{array}$ & $\begin{array}{r}0.43 \\
0.06 \\
-1.04 \\
-0.21\end{array}$ & 16 & 30 & 19.34 & -0.47 \\
\hline 360 & $\left.\begin{array}{c}15 \mathrm{hr} \\
92 \mathrm{hr} \\
165 \mathrm{hr} \\
200 \mathrm{hr} \\
400 \mathrm{hr}\end{array}\right\}$ & 6 & - & 11.82 & -3.61 & $\begin{array}{r}31 \\
33 \\
5 \\
37 \\
42 \\
43\end{array}$ & $\begin{array}{l}30 \\
26 \\
- \\
29 \\
74 \\
81\end{array}$ & $\begin{array}{c}18.07 \\
18.06 \\
19.15 \\
- \\
-\end{array}$ & $\begin{array}{c}-0.52 \\
-0.53 \\
0.56 \\
- \\
- \\
-\end{array}$ & $\begin{array}{r}27 \\
9 \\
7 \\
8 \\
30 \\
29 \\
29\end{array}$ & $\begin{array}{l}91 \\
- \\
98 \\
- \\
94 \\
-\end{array}$ & $\begin{array}{l}20.15 \\
21.00 \\
21.26 \\
21.01 \\
21.61 \\
21.02\end{array}$ & $\begin{array}{l}0.42 \\
1.27 \\
1.53 \\
1.28 \\
1.88 \\
1.29\end{array}$ & $\begin{array}{r}18 \\
9 \\
13 \\
17 \\
19\end{array}$ & $\begin{array}{l}57 \\
58 \\
65 \\
- \\
80\end{array}$ & $\begin{array}{c}18.99 \\
-. \\
19.23 \\
19.49 \\
-\end{array}$ & $\begin{array}{c}- \\
-0.82 \\
- \\
-0.58 \\
-0.32 \\
-\end{array}$ \\
\hline 370 & $15 \mathrm{hr}$ & & & & & 35 & 58 & 18.98 & 0.39 & & & & & & & & \\
\hline 380 & $15 \mathrm{hr}$ & & & & & $\begin{array}{l}13 \\
25 \\
39\end{array}$ & $\begin{array}{l}82 \\
83 \\
85 \\
\end{array}$ & $\begin{array}{c}19.44 \\
20.54 \\
-\end{array}$ & $\begin{array}{c}0.85 \\
1.95 \\
-\end{array}$ & & & & & & & & \\
\hline 400 & 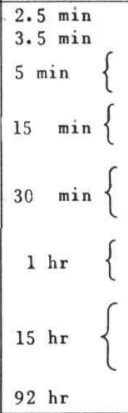 & $\begin{array}{l}10 \\
16 \\
20\end{array}$ & $\begin{array}{l}98 \\
96\end{array}$ & $\begin{array}{l}5.66 \\
3.50 \\
6.04\end{array}$ & $\begin{array}{r}-9.77 \\
-11.93 \\
-9.39\end{array}$ & $\begin{array}{r}44 \\
45 \\
46 \\
47 \\
47 \\
9 \\
17 \\
29 \\
27 \\
41 \\
48\end{array}$ & $\begin{array}{c}36 \\
55 \\
67 \\
67 \\
77 \\
94 \\
97 \\
- \\
- \\
93 \\
100\end{array}$ & $\begin{array}{c}- \\
- \\
- \\
- \\
- \\
20.96 \\
22.01 \\
22.10 \\
22.07 \\
-\end{array}$ & $\begin{array}{l}- \\
- \\
- \\
- \\
- \\
2.37 \\
4.42 \\
3.51 \\
3.48 \\
-\end{array}$ & $\begin{array}{l}35 \\
25 \\
20 \\
36 \\
12 \\
13 \\
37 \\
14 \\
15 \\
22 \\
16 \\
17 \\
1 \\
3\end{array}$ & $\begin{array}{l}49 \\
62 \\
- \\
82 \\
81 \\
- \\
85 \\
- \\
- \\
88 \\
91 \\
- \\
99 \\
-\end{array}$ & $\begin{array}{r}20.51 \\
20.76 \\
- \\
20.62 \\
20.99 \\
- \\
22.80 \\
22.33 \\
21.39 \\
23.54 \\
24.87 \\
25.57 \\
24.27\end{array}$ & $\begin{array}{l}- \\
0.78 \\
1.03 \\
-.89 \\
0.89 \\
1.6 \\
-.07 \\
3.07 \\
2.60 \\
1.66 \\
3.81 \\
5.14 \\
5.84 \\
4.54\end{array}$ & 12 & 84 & 20.44 & 0.63 \\
\hline 450 & $15 \mathrm{hr}$ & $\begin{array}{r}4 \\
14\end{array}$ & 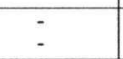 & $\begin{array}{l}5.57 \\
8.17\end{array}$ & $\begin{array}{l}-8.96 \\
-7.26\end{array}$ & $\begin{array}{r}3 \\
21\end{array}$ & 100 & $\begin{array}{l}22.14 \\
22.49\end{array}$ & $\begin{array}{l}3.55 \\
3.90\end{array}$ & & & & & 14 & 100 & 21.67 & 1.86 \\
\hline 600 & $15 \mathrm{hr}$ & 18 & - & 3.83 & -11.60 & 11 & - & 22.27 & 3.68 & & & & & & & & \\
\hline
\end{tabular}

*All volume percent recrystallization measurements were obtained from metallographic surfaces prepared parallel to the rolling direction and perpendicular to the plane of rolling.

... Mean expansion coefficient value is the average of three determinations as follows: specimen HP- $2-2=19.73 \mathrm{in} . / \mathrm{in} . /{ }^{\circ} \mathrm{C}$, specimen $\mathrm{HP}-2-11=20.38 \mathrm{in} . / \mathrm{in} . /{ }^{\circ} \mathrm{C}$ and specimen $\mathrm{HP}-2-26=19.07 \mathrm{in} . / \mathrm{in} . /{ }^{\circ} \mathrm{C}$ "Dash (-) indicates that the measurements were not made. 
Figure 3. Volume Percent Recrystallization of HP-I Specimens Annealed for a Constant Time Interval of 15 Hours at Various Temperatures.
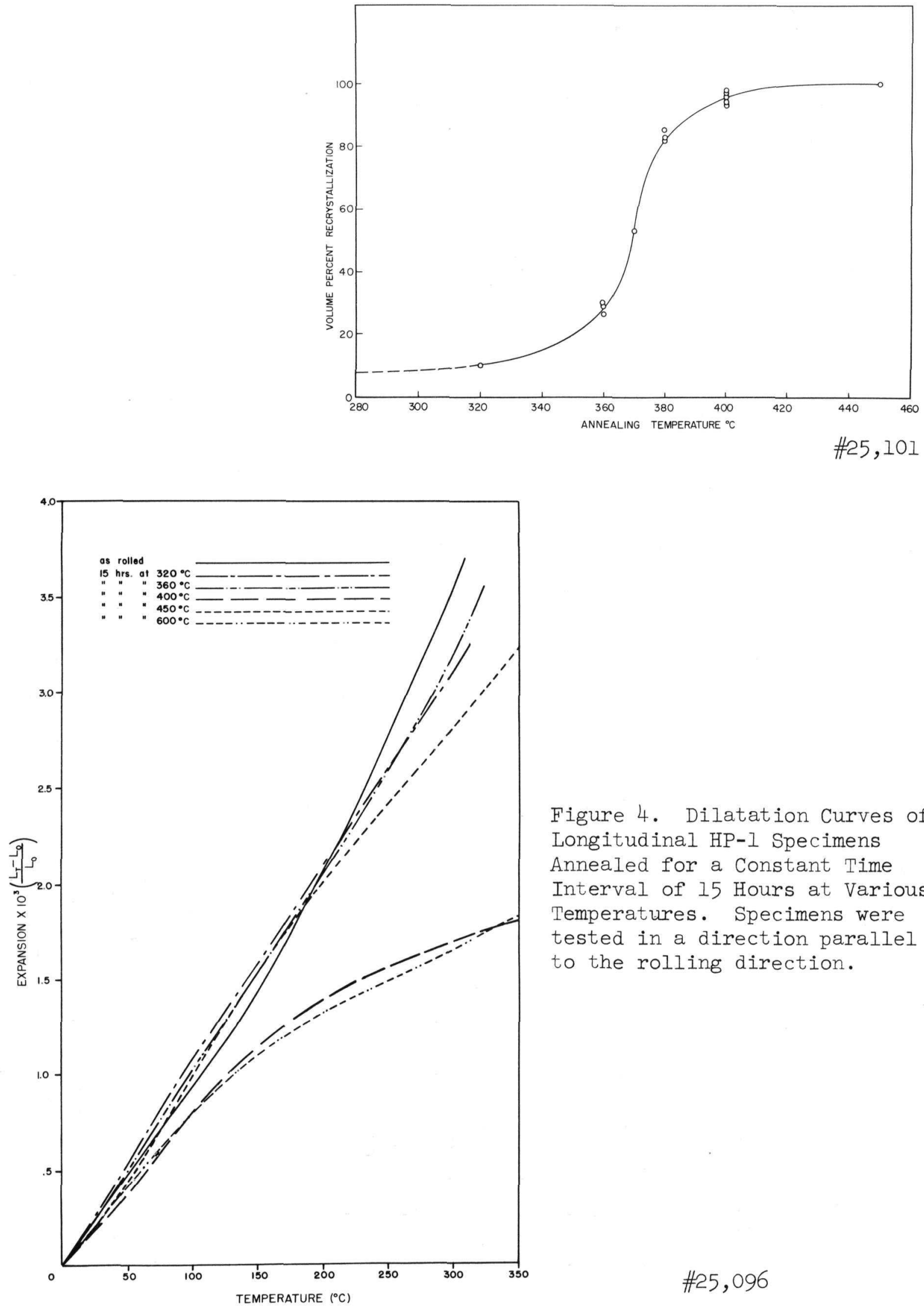

Figure 4. Dilatation Curves of Longitudinal HP-I Specimens Annealed for a Constant Time Interval of 15 Hours at Various Temperatures. Specimens were tested in a direction parallel to the rolling direction. 


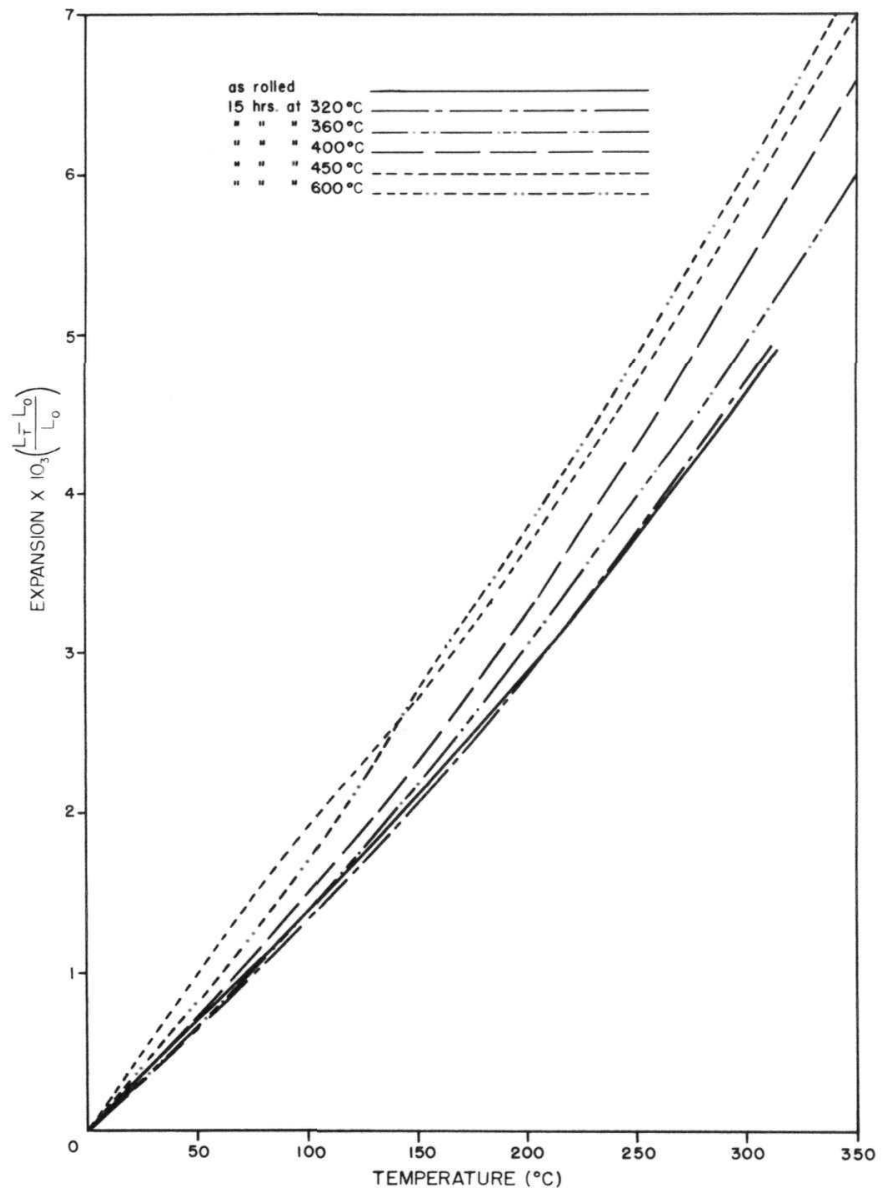

$\# 25,097$
Figure 5. Dilatation Curves of Transverse HP-I Specimens Annealed for a Constant Time Interval of 15 Hours at Various Temperatures. Specimens were tested in a direction perpendicular to the rolling direction and lying in the rolling plane.

Figure 6, where the long dimension represents the dilatation testing direction. It is obvious that the transverse specimen encompasses more bands of the heterogeneously deformed structure than does the longitudinal; therefore, the former yields a more statistically valid dilatation curve. For this reason, all subsequent thermal expansion curves were obtained from transverse specimens.

Data for the change of mean expansion coefficient between $200^{\circ}$ and $300^{\circ} \mathrm{C}$, as compared with that obtained from an as-rolled specimen, as a function of the volume percent recrystallization of HP-1 transverse specimens annealed for 15 hours at various temperatures are plotted in Figure 7. The change of expansion coefficient is obviously not a linear function of percent recrystallization. No significant change occurred until recrystallizations of more than $80 \%$ were obtained by annealing at $380^{\circ} \mathrm{C}$. Annealing treatments at temperature above this resulted in appreciable changes of the expansion coefficient. From these results, the effects of volume percent recrystallization and annealing temperature upon the change in mean expansion coefficient cannot be separated. Consequently, the remaining work was performed on specimens annealed for long times at low temperatures and short times at high temperatures to yield specimens with relatively high percents of recrystallization. 
Figure 6. HP-1 Specimens Annealed for 15 Hours at $360^{\circ} \mathrm{C}$, Tested in The Dilatometer and Macroetched.

a. Transverse specimen

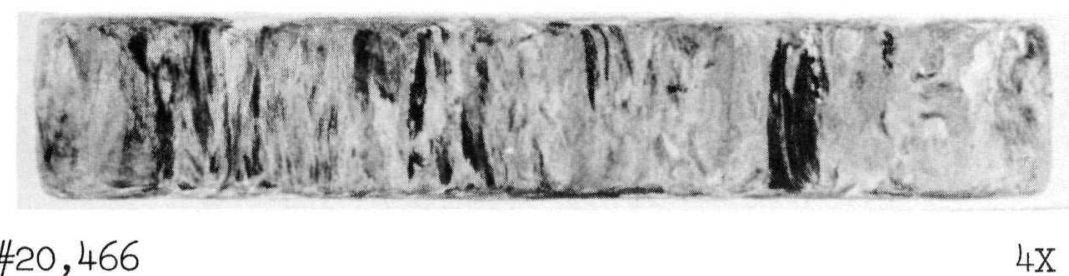

b. Longitudinal specimen

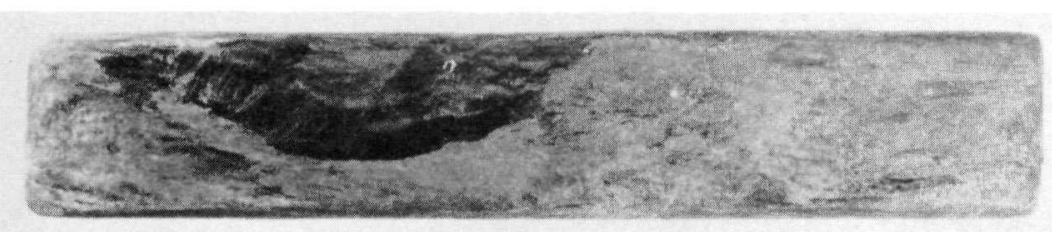

$\# 20,468$

$4 \mathrm{X}$

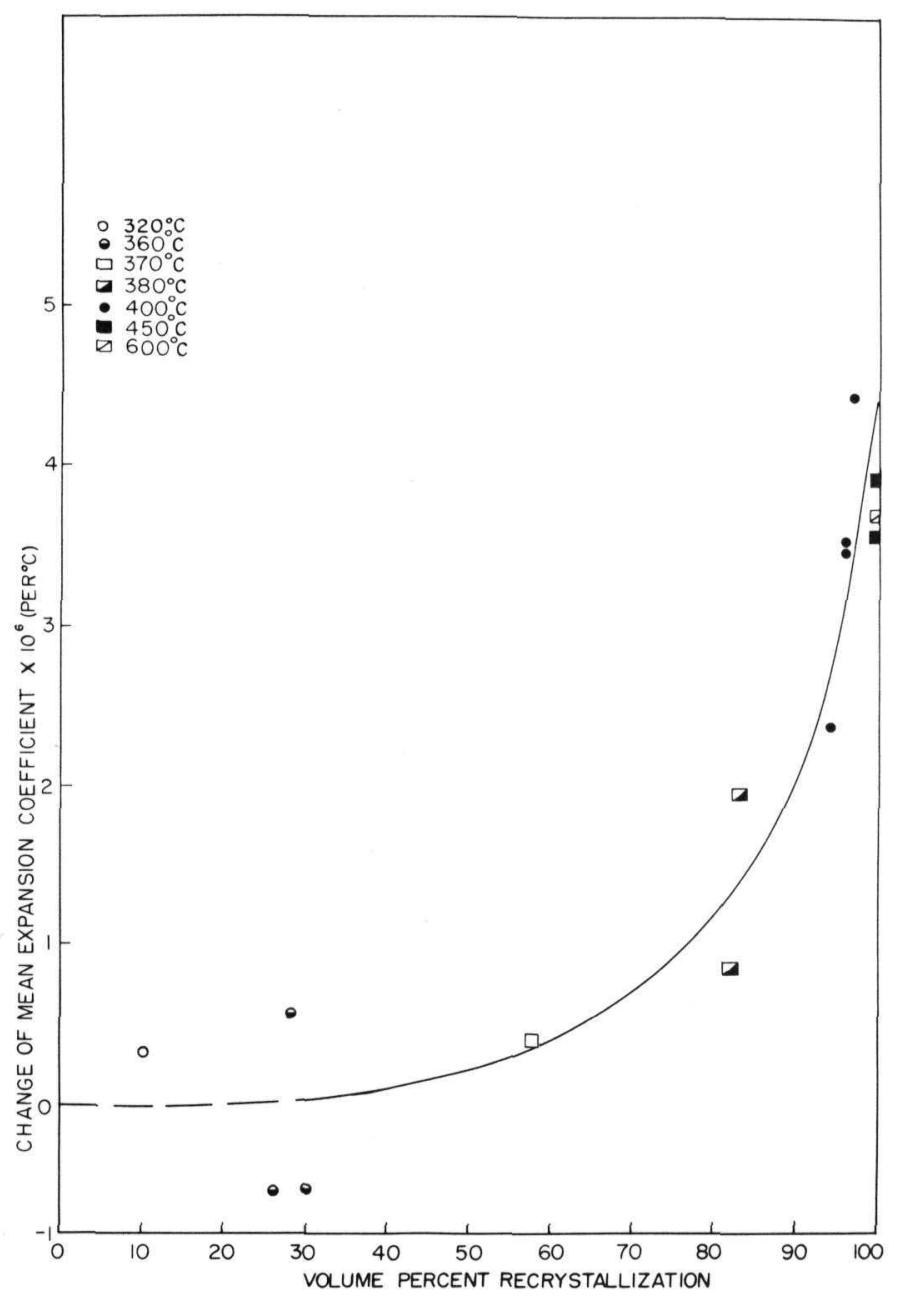

Figure 7 . Change of Mean Expansion Coefficient between $200^{\circ}$ and $300^{\circ} \mathrm{C}$, over that Obtained from an As-rolled Specimen, as a Function of Volume Percent Recrystallization for Transverse HP-I Specimens Annealed 15 Hours at Various Temperatures. 
In Figure 8 and 9 are plotted the volume percents of recrystallization of specimens from each of the three material fabrications as a function of the logarithm of annealing time at $360^{\circ}$ and $400^{\circ} \mathrm{C}$, respectively. The interesting feature of these plots is the difference in the amount of recrystallization observed for the same annealing treatments. Specimens of HP-2 recrystallized more rapidly than did those of HP-1. The latter,

Figure 8. Volume Percent Recrystallization of Specimens from the Three Material Fabrications as a Function of Annealing Time at $360^{\circ} \mathrm{C}$.

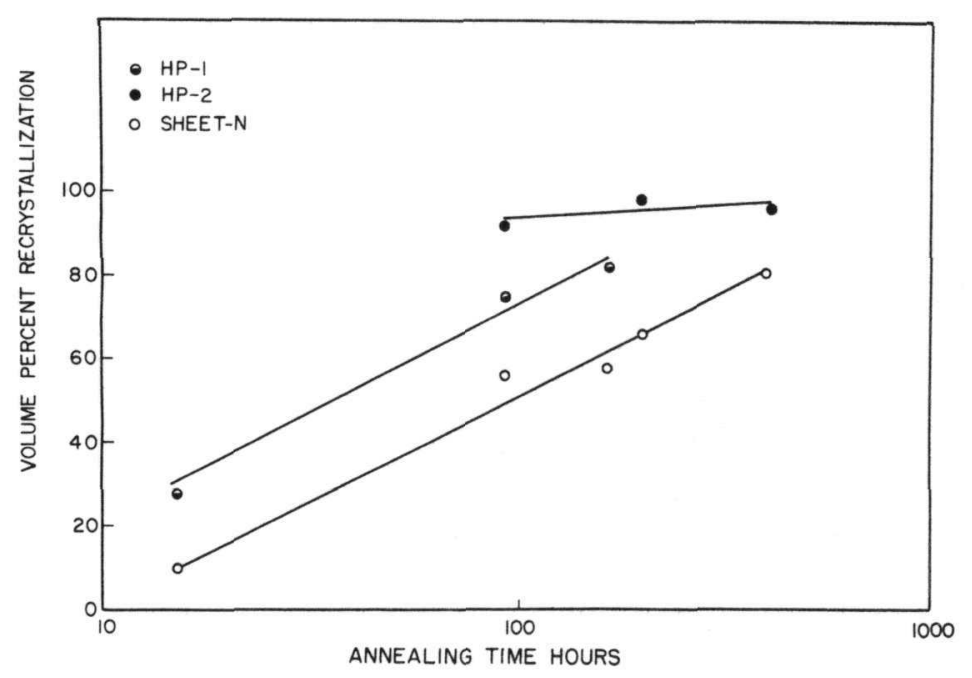

\#25,103

Figure 9. Volume Percent Recrystallation of Specimens from the Three Material Fabrications as a Function of Annealing Time at $400^{\circ} \mathrm{C}$.

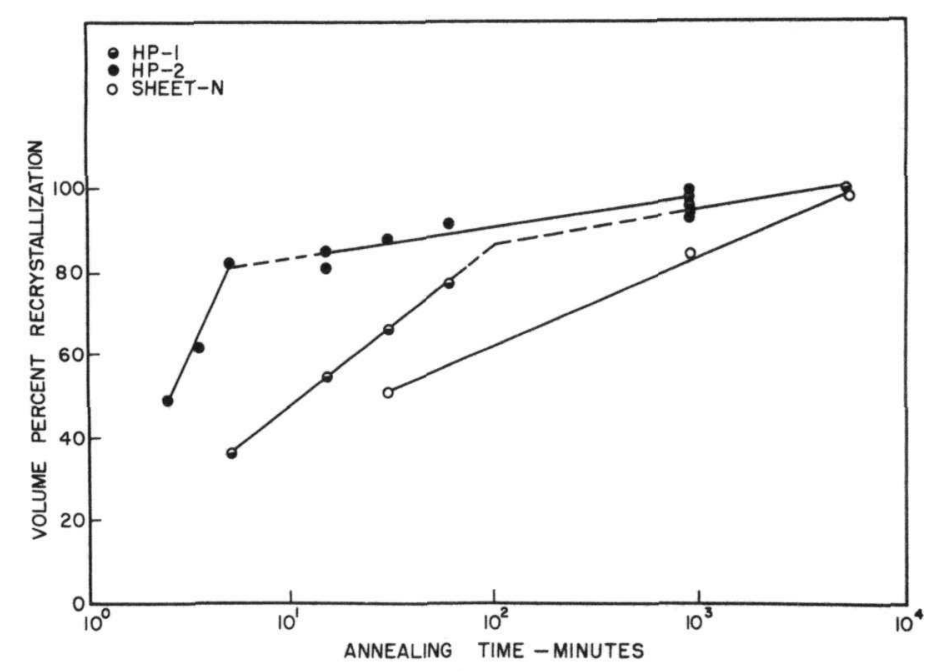

\#25,102 
in turn, recrystallized more rapidly than did sheet $\mathrm{N}$ specimens. The higher impurity content of sheet $\mathrm{N}$ explains its smaller volume of $\mathrm{re}$ crystallization. Since both of the HP specimens were prepared from the same ingot, chemical composition cannot explain their difference. The only plausible variable is the procedure used for preparation of the two samples. Every attempt was made to duplicate their preparations with the exception of the roll size for the $80 \%$ reduction at room temperature. Apparently the smaller roll diameter used to fabricate HP-2 resulted in a larger quantity of residual internal stresses within the rolled sheet.

Another interesting feature of the plot of data for HP materials in Figure 9 is the apparent representation of each set by two straight lines. Such behavior is indicative of two processes of recrystallization. Also, the discontinuities occur at approximately $80 \%$ recrystallization. This is in agreement with the discontinuity observed in the plot of change in mean coefficient of expansion as a function of volume percent of recrystallization for specimens annealed at $400^{\circ} \mathrm{C}$ (Figure 10).

Figures 10 and 11 show data for the change of the mean coefficients of expansion as a function of the volume percent of recrystallization of $\mathrm{HP}-2$ and sheet $\mathrm{N}$ specimens, respectively. The most significant feature of Figure 10 is that, by annealing for long periods of time at $360^{\circ} \mathrm{C}$, as high as $98 \%$ recrystallization can be obtained with only a small change in expansion coefficient. If, however, specimens are annealed at $400^{\circ} \mathrm{C}$ to comparable recrystallizations, an appreciable change is observed in the expansion coefficient. Annealing for 15 minutes or less at $400^{\circ} \mathrm{C}$ produced changes in expansion coefficient similar to those observed for comparable recrystallizations obtained by annealing at lower temperatures. The magnitudes of the changes in the expansion coefficient of HP -2 material annealed at $400^{\circ} \mathrm{C}$ to almost complete recrystallization were greater than those for similar HP 1 specimens. The changes in expansion coefficient for sheet $\mathrm{N}$ specimens were considerably smaller than those for the HP-2 material, Sheet $\mathrm{N}$ specimens annealed at temperatures below $400^{\circ} \mathrm{C}$ showed negative changes, whereas ones annealed at $400^{\circ}$ or $450^{\circ} \mathrm{C}$ showed essentially zero and positive changes, respectively. The small quantity of this material that was available did not permit extensive experimentation; however, its behavior appears to be quite similar to that of the HP materials.

In an attempt to determine the stability of the recrystallized structure obtained from a particular annealing treatment, some of the dilatometric specimens were subjected to second and third anneals and observed for changes in mean coefficient of expansion and yolume percent of recrystallization; the data for these are given in Table IV. In general, if the prior heat treatment had resulted in nearly $100 \%$ recrystallization, an additional anneal did not affect the change in expansion coefficient; however, if the sample was not completely recrystallized by the first treatment, a change did occur. The exceptions to this are for the third treatments of 


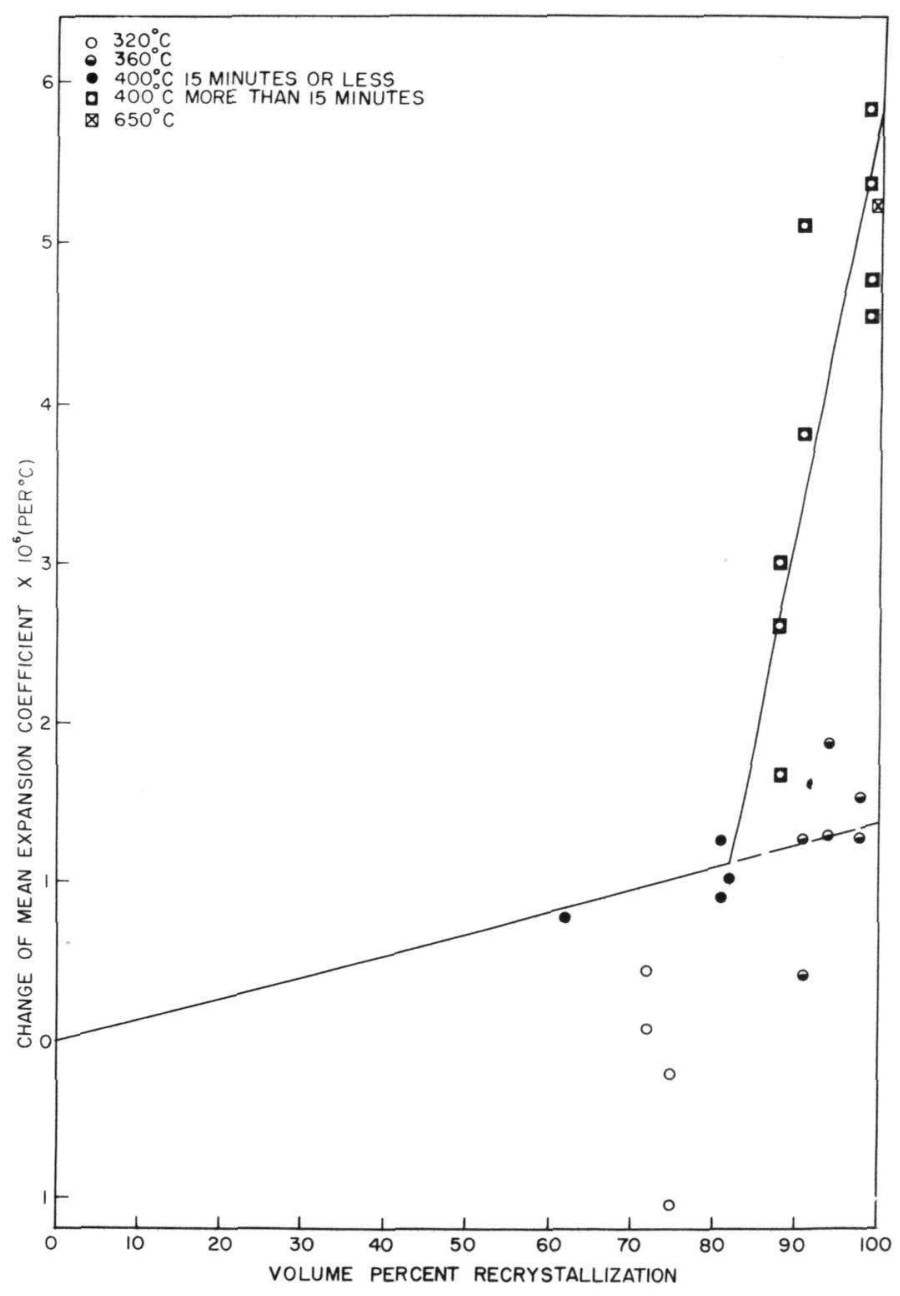

Figure 10. Change of Mean Expansion Coefficient between $200^{\circ}$ and $300^{\circ} \mathrm{C}$, over that $\mathrm{Ob}-$ tained from an As-rolled Specimen, as a Function of Volume Percent Recrystallization for Transverse HP-2 Specimens Annealed for Varying Periods of Time at Various Temperatures.

\#25,098

Figure 11. Change of Mean Expansion Coefficient between $200^{\circ}$ and $300^{\circ} \mathrm{C}$, over that Obtained from an As-rolled Specimen, as a Function of Volume Percent Recrystallization for Transverse Sheet N Specimens Annealed for Varying Periods of Time at Various Temperatures.

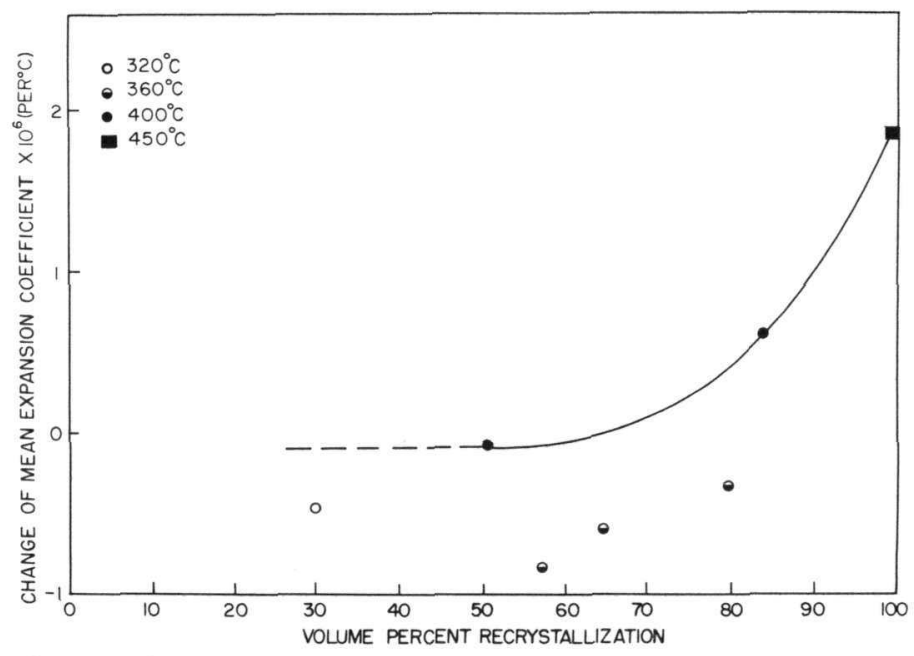

$\# 25,099$ 
TABLE IV

Volume Percent Recrystallization and Change in

Mean Expansion Coefficient for Specimens Given

Second and Third Annealing Treatments

\begin{tabular}{|c|c|c|c|c|}
\hline $\begin{array}{l}\text { Specimen } \\
\text { Number }\end{array}$ & $\begin{array}{c}\text { Temperature } \\
\left({ }^{\circ} \mathrm{C}\right)\end{array}$ & Time & $\begin{array}{l}\text { Volume } \\
\text { Percent } \\
\text { Recrys- } \\
\text { tallization }\end{array}$ & $\begin{array}{c}\text { Change } \\
\text { of Mean } \\
\text { Expansion } \\
\text { Coefficient } \\
\left(x 10^{6} \text { per }{ }^{\circ} \mathrm{C}\right)\end{array}$ \\
\hline \multicolumn{5}{|c|}{ First Annealing Treatment } \\
\hline $\begin{array}{l}\text { HP-2-31 } \\
\text { HP-2- } 8 \\
\text { HP-2-13 } \\
N-14 \\
\text { HP-2-6 } \\
\text { HP-2-14 }\end{array}$ & $\begin{array}{l}320 \\
360 \\
400 \\
450 \\
320 \\
400\end{array}$ & $\begin{array}{l}400 \mathrm{hr} \\
200 \mathrm{hr} \\
15 \mathrm{~min} \\
15 \mathrm{hr} \\
200 \mathrm{hr} \\
30 \mathrm{~min}\end{array}$ & $\begin{array}{r}85 \\
98 \\
81 \\
100 \\
72 \\
88\end{array}$ & $\begin{array}{r}-0.21 \\
1.21 \\
0.89 \\
1.86 \\
0.43 \\
3.07\end{array}$ \\
\hline \multicolumn{5}{|c|}{ Second Annealing Treatment } \\
\hline $\begin{array}{l}\text { HP-2-31 } \\
\text { HP-2-8 } \\
\text { HP-2-1 } 3 \\
\text { N-14 } \\
\text { HP-2-6 } \\
\text { HP-2-14 }\end{array}$ & $\begin{array}{l}400 \\
400 \\
400 \\
600 \\
650 \\
650\end{array}$ & $\begin{array}{l}15 \mathrm{hr} \\
15 \mathrm{hr} \\
15 \mathrm{hr} \\
15 \mathrm{hr} \\
48 \mathrm{hr} \\
48 \mathrm{hr}\end{array}$ & $\begin{array}{r}\sim 100 \\
\sim 100 \\
\sim 100 \\
100 \\
100 \\
100\end{array}$ & $\begin{array}{l}4.77^{*} \\
1.21 \\
5.38 \\
1.94 \\
5.22 \\
6.89\end{array}$ \\
\hline \multicolumn{5}{|c|}{ Third Annealing Treatment } \\
\hline $\begin{array}{l}\text { HP-2-31 } \\
\text { HP- } 2-8 \\
\text { HP- } 2-11 \\
N-14 \\
\text { HP-2-6 } \\
\text { HP-2- } 14\end{array}$ & $\begin{array}{c}650 \\
- \\
650 \\
- \\
- \\
-\end{array}$ & $\begin{array}{l}48 \mathrm{hr} \\
- \\
48 \mathrm{hr} \\
- \\
- \\
-\end{array}$ & $\begin{array}{c}100 \\
- \\
100 \\
- \\
- \\
-\end{array}$ & $\begin{array}{c}6.23 * \\
- \\
7.27 \\
- \\
- \\
-\end{array}$ \\
\hline
\end{tabular}

*Changes in mean expansion coefficients reported for second and third heat treatments are the changes in mean expansion coefficient over that of an as-rolled specimen and not that of the previous heat treatment. 
specimens $\mathrm{HP}-2-13$ and $\mathrm{HP}-2-31$, wherein $48-$ hour anneals at $650^{\circ} \mathrm{C}$ do change the expansion coefficient. Grain coarsening definitely occurred in these cases. Similar behavior was observed for the second anneals of specimens $H P-2-6$ and $H P-2-14$.

\section{Metallographic Observations}

The as $\rightarrow$ rolled and annealed microstructures of the three materials were extremely heterogeneous. Considerable variations were noted within individual specimens: however, all three materials yielded similar observations with regard to the types of structures present and their behavior upon annealing. The observations of $\mathrm{HP}$ and sheet $\mathrm{N}$ materials are separated in the following purely for convenience. All the photomicrographs, except where noted, are mounted with the rolling direction vertical and were obtained from surfaces polished parallel to the rolling direction and perpendicular to the rolling planes (longitudinal section).

1. HP as-rolled structures: The banded HP as-rolled structure is illustrated in Figure 12. No appreciable differences were observed for longitudinal or transverse (perpendicular to the rolling direction and rolling planes) sections of the as-rolled or annealed specimens. The types of deformed structure zones whose behavior can be followed, at least in part, throughout the various annealing treatments are labeled in Figure 12. Each zone probably originated from a grain present prior to fabrication at room temperature. The differences in appearances of the zones arise from variations in their deformation modes, as indicated by their orientations with respect to the deforming forces.(4)

Seventy volume percent of the HP-1 as-rolled structure was similar to the area designated as $A$ in Figure 12a. It is fibrous in appearance and, undoubtedly, represents the most heavily deformed portions, since the average microhardness was 386 VHN (Vickers hardness number). The next most prevalent deformed structure was zone $B_{\text {; }}$ it occupied 15 volume percent, had a hardness of $335 \mathrm{VHN}_{\text {, }}$ and appeared similar to the peppery or "speckled" areas described by Cabane and Petit(1) and Madsen.(5) The distinct, narrow, bent bands of zone C occupied 13 percent of the structure and had a hardness of $365 \mathrm{VHN}$. The remaining 2 percent appeared similar to that designated as $D$ in Figure $12 \mathrm{~b}$. This zone had the lowest hardness (205 VHN) and represented lightly deformed material. The structure of $\mathrm{HP}_{-} 2$ as $\mathrm{s}$ rolled specimens were similar to those of $H_{\infty} 1$ specimens: however, variations were noted in the amounts of the different zones. As-rolled HP-2 specimens contained $43 \%$ zone A, $36 \%$ zone $\mathrm{B}, 18 \%$ zone $\mathrm{C}$ and $3 \%$ zone $\mathrm{D}$. 
Figure 12. Microstructures of As-rolled HP-1 Specimens Showing Types of Deformed Structure Zones.

a. Transverse section
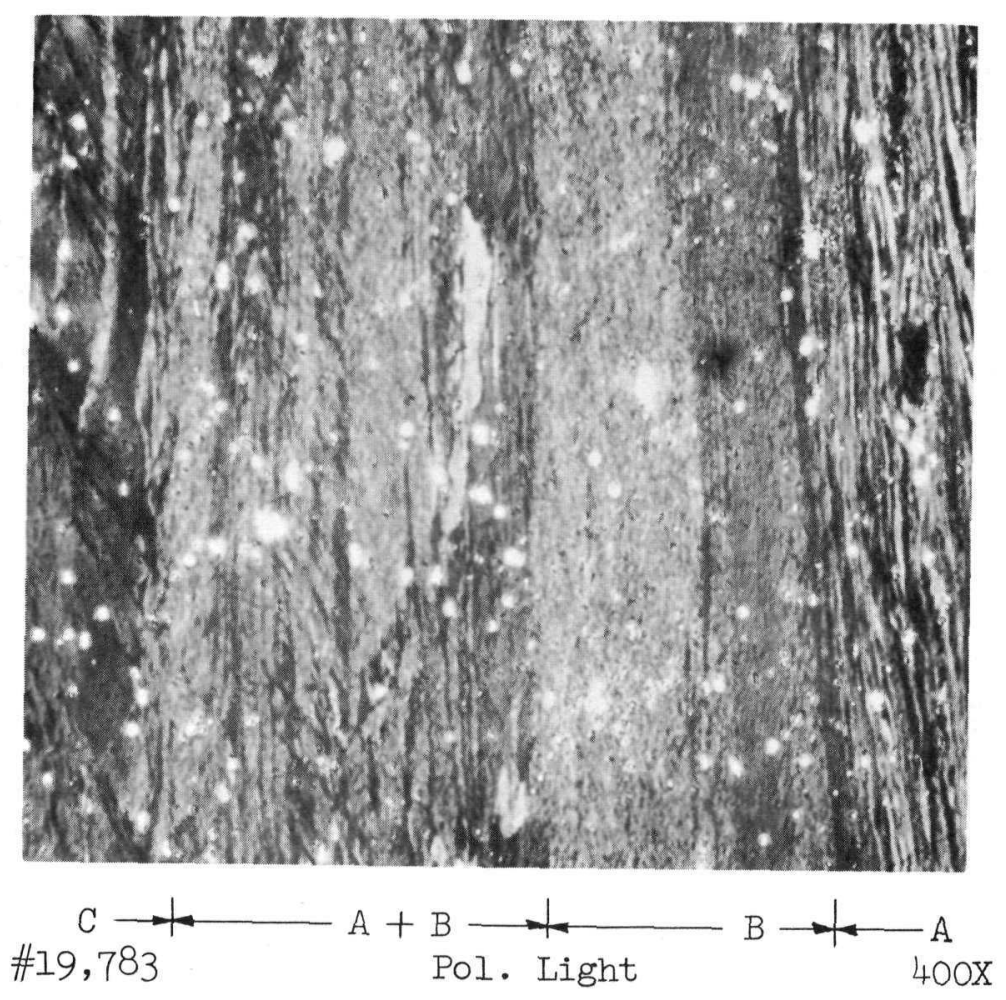

b. Longitudinal section

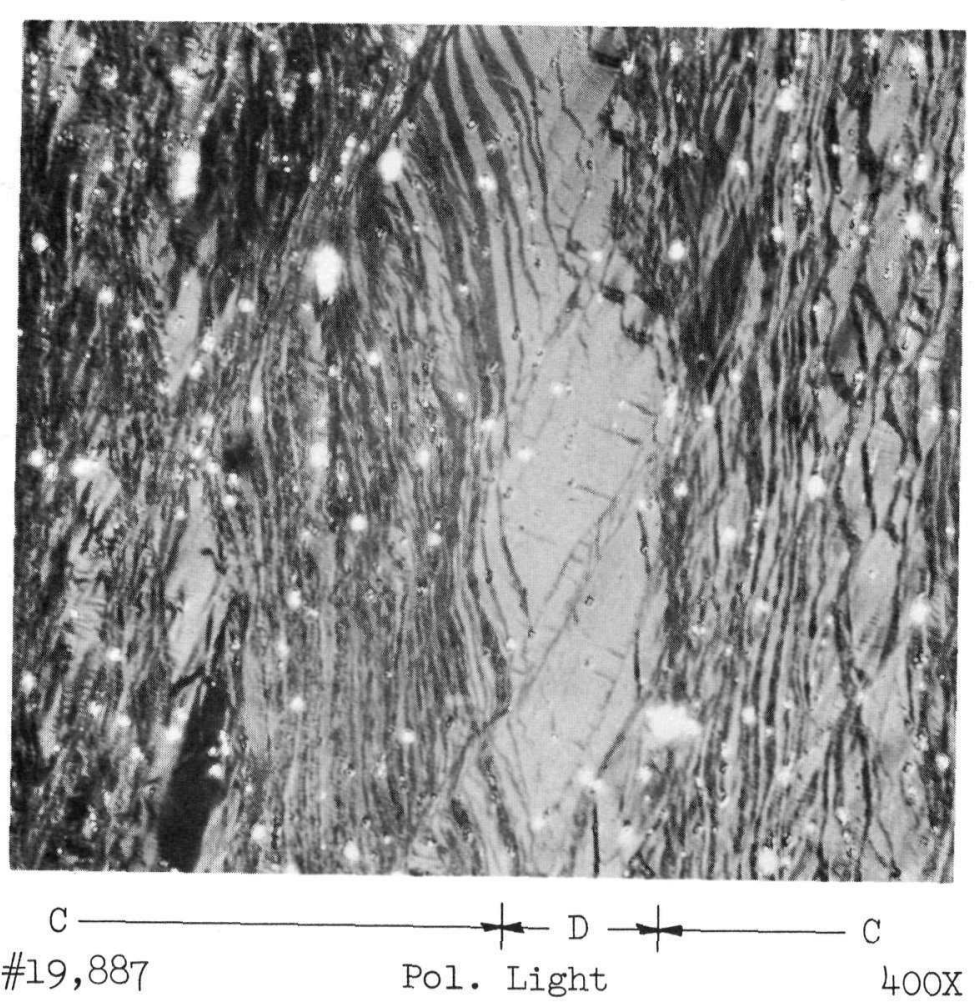


Figure 13. Microstructures of HP-I Specimens Annealed 15 Hours at Various Temperatures.

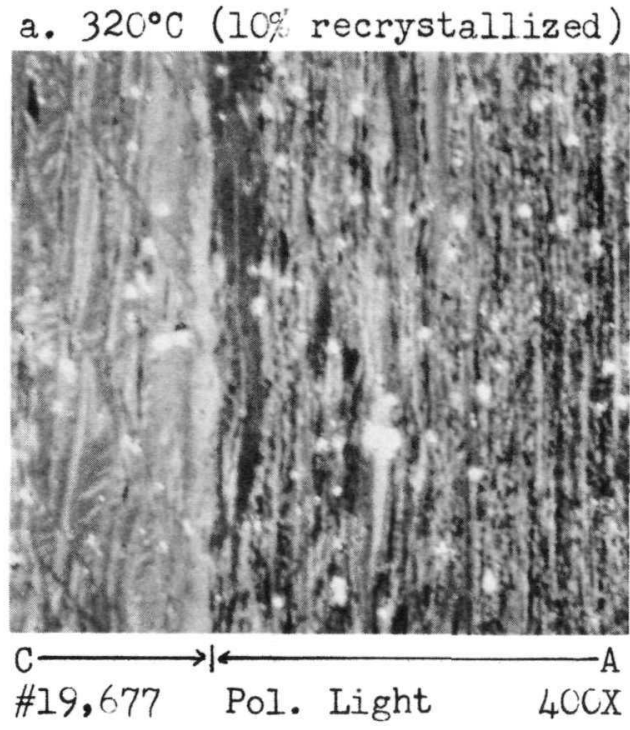

c. $370^{\circ} \mathrm{C}(58 \%$ recrystallized)

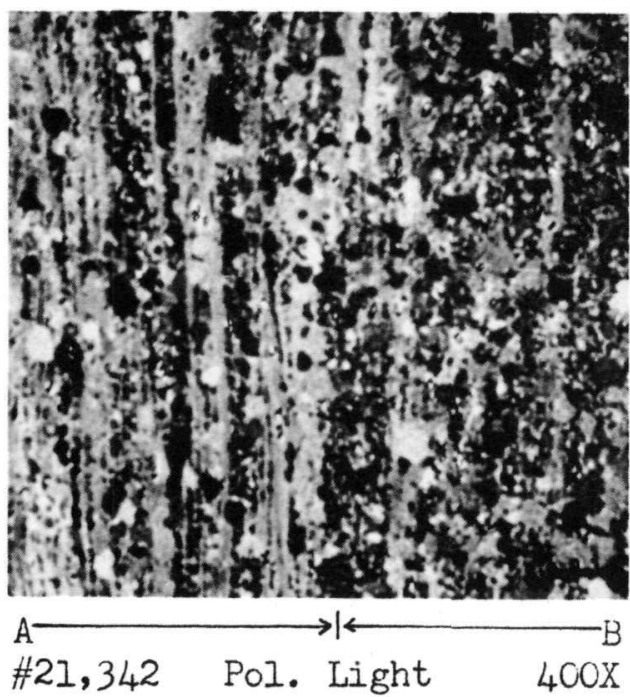

e. $400^{\circ} \mathrm{C}(95 \%$ recrystallized)
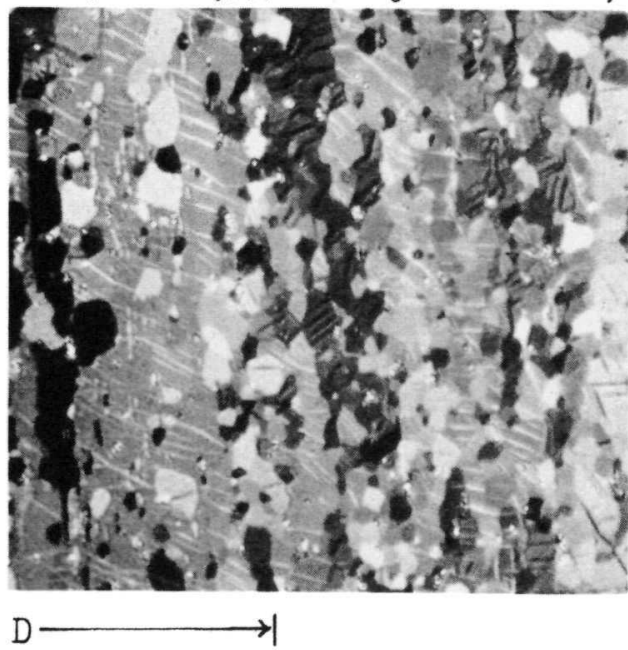

\#19,686 Pol. Light 400X

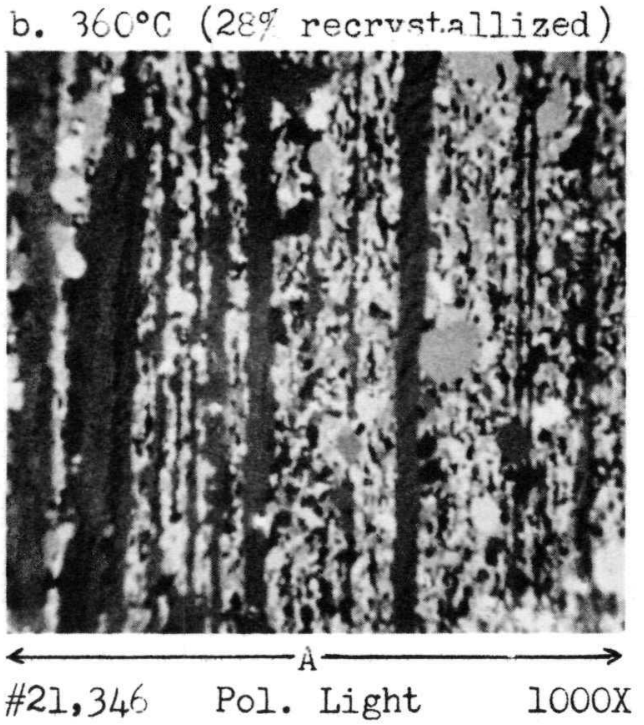

d. $380^{\circ} \mathrm{C}(83 \%$ recrystallized $)$

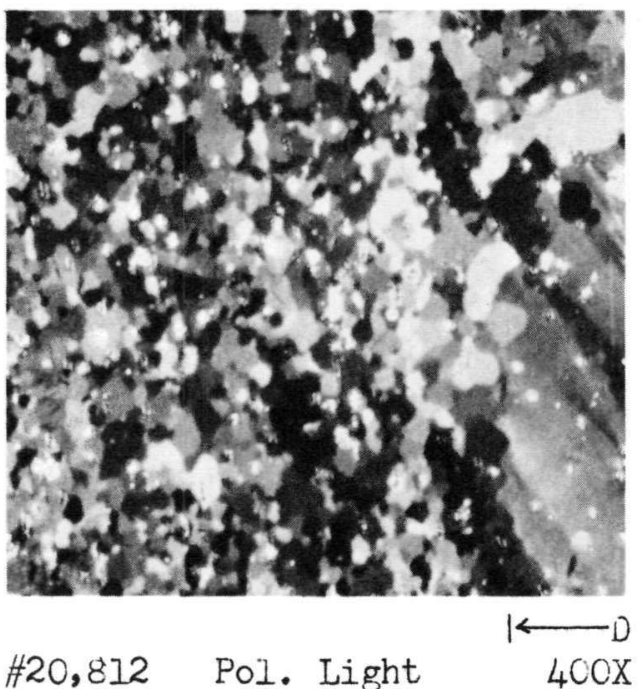

f. $450^{\circ} \mathrm{C}(100 \%$ recrystallized)

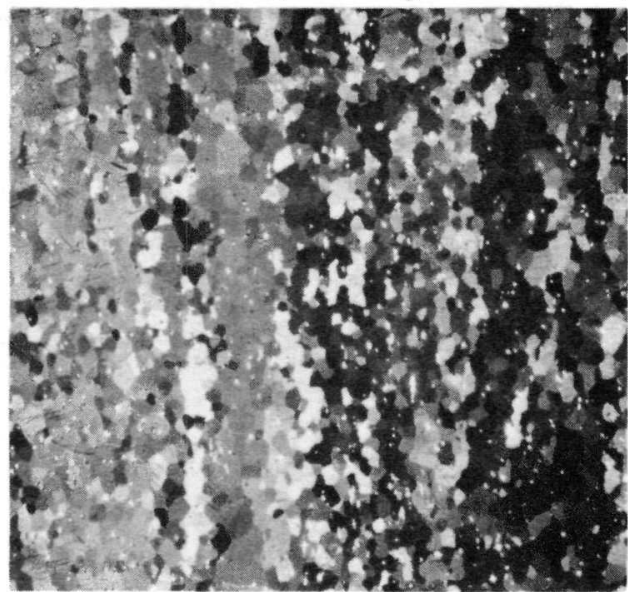

\#19,689 Pol. Light

$150 \mathrm{X}$ 
2. Structures of HP specimens annealed 15 hours at various

temperatures: Microstructures of HP-1 material annealed 15 hours at various temperatures are shown in Figure 13. These do not represent all the types of structures found in the specimens, but they serve to illustrate the main observations.

After annealing at $320^{\circ} \mathrm{C}$ (Figure $13 \mathrm{a}$ ) very fine recrystallized grains appeared in A zones. These were arranged in bands elongated in the rolling direction and could be resolved, with difficulty, only at magnifications of $1000 \mathrm{X}$ or more. Annealing at $360^{\circ} \mathrm{C}$ (Figure $13 \mathrm{~b}$ ) caused an increase in the amount of recrystallization in zone $A$. The fine-grain areas were separated by bands of subgrained structure. In isolated cases, larger grains were found among the fine grains and appeared to be growing by absorption of the fine grains. These processes were enhanced by annealing at $370^{\circ} \mathrm{C}$ (Figure 13c). The amount of recrystallization increased, the quantity of subgrained. bands decreased and the sizes and quantities of grains growing at the expense of the fine recrystallized material increased, At this temperature it was difficult to distinguish between the original zone $\mathrm{A}$ and zone.B. After annealing at $380^{\circ} \mathrm{C}$ all zone A material was recrystallized, and almost all of the fine grains had been absorbed bylarger ones (Figure 13d). Annealing at higher temperatures caused a general increase of the grain size.

Zone B areas also were partially recrystallized by annealing at $320^{\circ} \mathrm{C}$. The effect of increased annealing temperature was generally parallel to that of zone $A$ until the two became indistinguishable after annealing at $380^{\circ} \mathrm{C}$. Similar to the behavior of zone A, annealing at $360^{\circ} \mathrm{C}$ resulted in a beginning of absorption of the fine recrystallized material by the larger grains.

Annealing at $320^{\circ} \mathrm{C}$ caused an increase in contrast between the bands present in zone C (Figure 13a). This contrast increased as the annealing temperature was increased to $360^{\circ}$ and $370^{\circ} \mathrm{C}$. In many cases the areas appeared subgrained, as if associated with kink bands and their polygonization by recovery processes. This type of structure is illustrated in Figure $16 \mathrm{~b}$ for a specimen annealed 92 hours at $360^{\circ} \mathrm{C}$. After annealing at $380^{\circ} \mathrm{C}$ recrystallization began to occur in zone $\mathrm{C}$ and an anneal at $400^{\circ} \mathrm{C}$ was sufficient to complete the process.

No apparent changes were observed in zone $D$ areas until an annealing temperature of $380^{\circ} \mathrm{C}$ was reached (Figure 13b). Then such areas also began to show polygonization and, in some cases the presence of a few, small recrystallized grains located at twin-twin or twin-kink band intersections (Figure 17). This behavior was enhanced by annealing at $400^{\circ} \mathrm{C}$, but complete recrystallization did not occur until annealing at $450^{\circ} \mathrm{C}$. 
Recrystallized grains of the original, more heavily deformed zones A and B did not appear to grow into the lightly deformed zones $C$ and $D_{0}$ instead, the latter two areas developed their own recrys tallization "nuclei" after an anneal at sufficiently high temperatures. Specimens annealed for 15 hours at $450^{\circ} \mathrm{C}$ (Figure 13f) were completely recrystallized, with considerable banding being evident in the structure. The grain size varied from band to band, but within each area was comparable. Variations in contrast were evident between neighboring grains within a given band: some bands showed high contrast, whereas others showed very little. Annealing at $600^{\circ} \mathrm{C}$ caused an over-all increase in grain size but did not yield any evidence of grain coarsening.

3. Structures of HP specimens annealed for various times at different temperatures: The above description demonstrates the general behavior of the various deformed zones upon annealing. By the addition of a time variable, certain of these recrystallization processes are delineated more clearly.

Figure 14 shows photographs illustrating the recrystallization processes in the heavily deformed zones A and B. An area of predominantly fine grains with some unrecrystallized material is shown in Figure 14a. After 92 hours at $360^{\circ} \mathrm{C}$ larger grains were found in these areas and appeared to be growing from the fine grains (Figure 14b). An anneal for 165 hours resulted in a large portion of the small grains being absorbed by the larger ones, as shown in Figure 14c. After 400 hours at $360^{\circ} \mathrm{C}$ all of the fine grains had been consumed (Figure 14d). The formation and absorption of the fine grains occurred at different rates for the various deformed bands of a given specimen. Therefore, a particular deformed band may show recrystallization to fine grains, whereas the fine grains in the next band may be almost completely absorbed by the larger grains. Other bands showed various stages of the formation of fine grains and their absorption. This same phenomenon was observed for specimens annealed at temperatures as low as $320^{\circ}$ and as high as $400^{\circ} \mathrm{C}$. The primary differences were, obviously, the times necessary for completion of the process and the relative rates at which the very fine grains formed and at which they were absorbed by larger ones. These factors are illustrated in Table $\mathrm{V}$, wherein data for the total volume percent of recrystallization and volume percent of very fine recrystallized grains are tabulated. At $360^{\circ} \mathrm{C}$ the process was complete after 200 hours, whereas at $400^{\circ} \mathrm{C}$ it was nearly complete in 15 hours. A specimen an. nealed at $320^{\circ} \mathrm{C}$ for 400 hours showed $85 \%$ recrystallization but still had $70 \%$ fine grains. On the other hand, annealing for 15 minutes at $400^{\circ} \mathrm{C}$ to $85 \%$ recrystallization yielded only $14 \%$ fine grains. Annealing at this higher temperature increased the ratio of the large grains to the very fine grains. 
Figure 14. HP-1 Specimen Annealed at $360^{\circ} \mathrm{C}$ for Varying Periods of Time.

a. Annealed 15 hours
(30\% recrystallized)

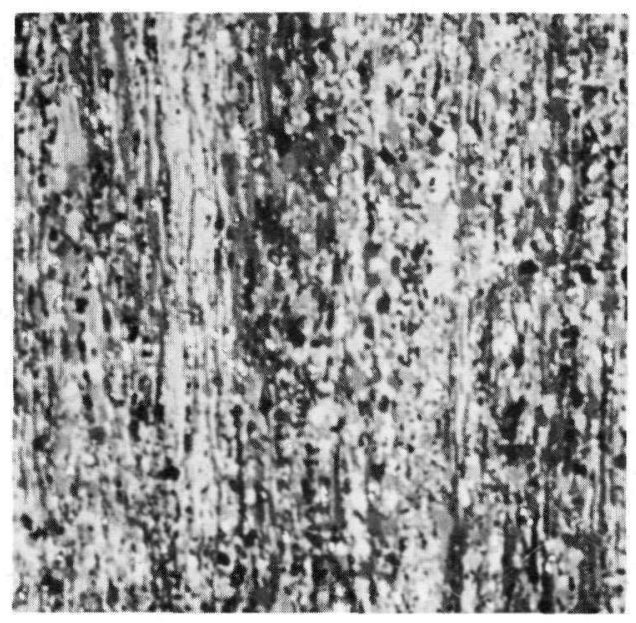

\#21,347 Pol. Light 400X b. Annealed 92 hours

( $74 \%$ recrystallized)

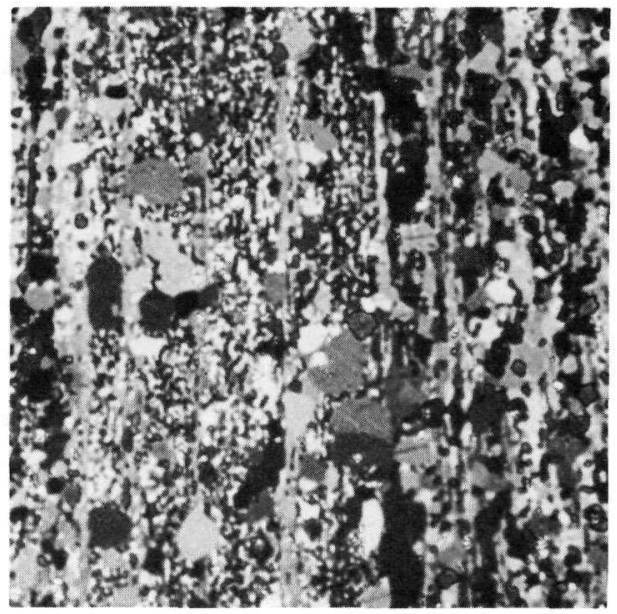

\#21,324 Pol. Light 400X c. Annealed 165 hours

( $81 \%$ recrystallized)

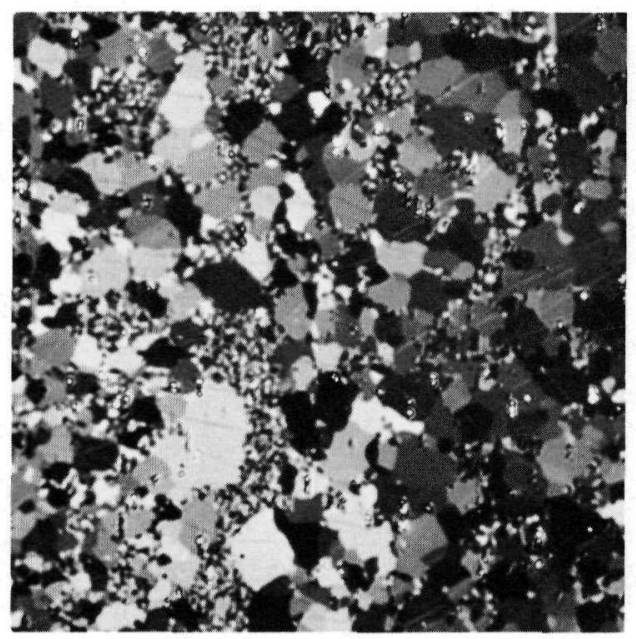

\#21,434 Pol. Light

$400 x$ d. Annealed 400 hours

( $94 \%$ recrystallized)

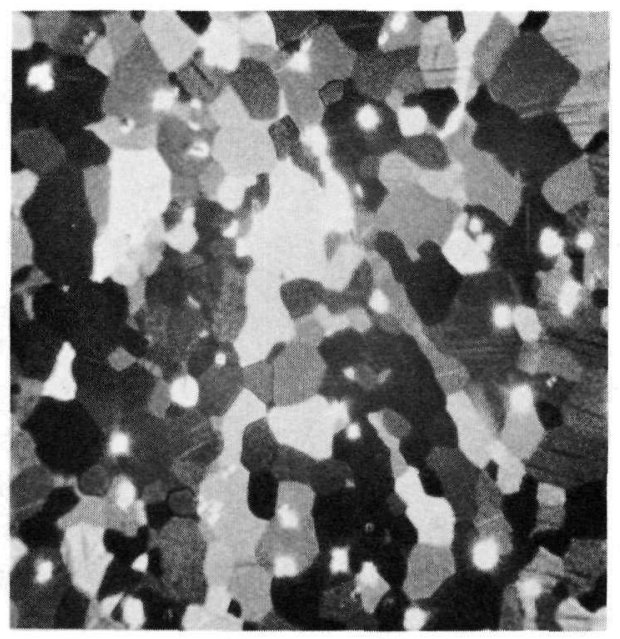

$\# 22,24 y$ rol. Light 1000X 
TABLE V

Effect of Annealing Treatment upon Amount of Speckled-Appearing Areas

\begin{tabular}{|c|c|c|c|c|c|c|c|}
\hline \multicolumn{2}{|c|}{$\begin{array}{l}\text { Annealing } \\
\text { Treatment }\end{array}$} & \multicolumn{2}{|c|}{ HP-1 Specimens } & \multicolumn{2}{|c|}{ HP-2 Specimens } & \multicolumn{2}{|c|}{ Sheet N Specimens } \\
\hline $\begin{array}{c}\text { Temper- } \\
\text { ature } \\
\left({ }^{\circ} \mathrm{C}\right)\end{array}$ & Time & $\begin{array}{l}\text { Volume } \\
\text { Percent } \\
\text { Recrys- } \\
\text { tallized }\end{array}$ & $\begin{array}{l}\text { Volume } \\
\text { Percent } \\
\text { Speckled }\end{array}$ & $\begin{array}{l}\text { Volume } \\
\text { Percent } \\
\text { Recrys- } \\
\text { tallized }\end{array}$ & $\begin{array}{l}\text { Volume } \\
\text { Percent } \\
\text { Speckled }\end{array}$ & $\begin{array}{l}\text { Volume } \\
\text { Percent } \\
\text { Recrys- } \\
\text { tallized }\end{array}$ & $\begin{array}{l}\text { Volume } \\
\text { Percent } \\
\text { Speckled }\end{array}$ \\
\hline \multicolumn{2}{|c|}{ As-rolled } & 0 & 15 & 0 & 36 & 0 & 20 \\
\hline 320 & $\begin{array}{l}200 \mathrm{hr} \\
400 \mathrm{hr}\end{array}$ & & & $\begin{array}{l}72 \\
85\end{array}$ & $\begin{array}{l}60 \\
70\end{array}$ & & \\
\hline 360 & $\begin{array}{r}15 \mathrm{hr} \\
92 \mathrm{hr} \\
200 \mathrm{hr}\end{array}$ & 30 & 25 & $\begin{array}{l}91 \\
98\end{array}$ & $\begin{array}{l}2 \\
0\end{array}$ & $\begin{array}{l}57 \\
65\end{array}$ & $\begin{array}{l}19 \\
11\end{array}$ \\
\hline 400 & $\begin{aligned} 2.5 \mathrm{~min} \\
5 \mathrm{~min} \\
15 \mathrm{~min} \\
30 \mathrm{~min} \\
15 \mathrm{hr} \\
92 \mathrm{hr}\end{aligned}$ & & & $\begin{array}{r}49 \\
82 \\
85 \\
88 \\
100\end{array}$ & $\begin{array}{l}24 \\
17 \\
14 \\
4.5 \\
2\end{array}$ & $\begin{array}{l}51 \\
99\end{array}$ & $\begin{array}{l}39 \\
0\end{array}$ \\
\hline
\end{tabular}

The changes in appearance of the fine grains as a result of various annealing treatments are illustrated in Figure 15. After 200 hours at $320^{\circ} \mathrm{C}$, the fine grains could be resolved at magnifications of $1000 \mathrm{X}$ or greater (Figure 15a). Increased time at temperature, or annealing for shorter times at higher temperatures, yielded a slightly larger grain size (Figures $15 b$ and $15 c$ ). Only a small quantity of the fine grains was observed in a specimen annealed 15 hours at $400^{\circ} \mathrm{C}$ (Figure $15 \mathrm{~d}$ ); these were eliminated by increasing the annealing time.

In general, the very fine grains were formed and, for the most part, were absorbed by the larger grains before recrystallization took place in the lightly deformed zones C and D. Typical examples of these zones in specimens annealed for relatively long times at low temperatures and for short times at high temperature are shown in Figure 16. Zone D areas recrystallized to grains as large as, or larger than, those created by absorption of the very fine grains (Figures 16a and 16d). As time and/or temperature of annealing was increased, the proportion of recrystallization also increased. The zone $\mathrm{C}$ areas generally showed the same behavior; however, prior to their final recrystallization, they appeared as subgrains (Figures $16 \mathrm{~b}$ and 16c). 
Figure 15. The Change in Appearance of Very Fine Recrystallized Grains in HP Specimens.

a. Annealed 200 hours at $320^{\circ} \mathrm{C}$
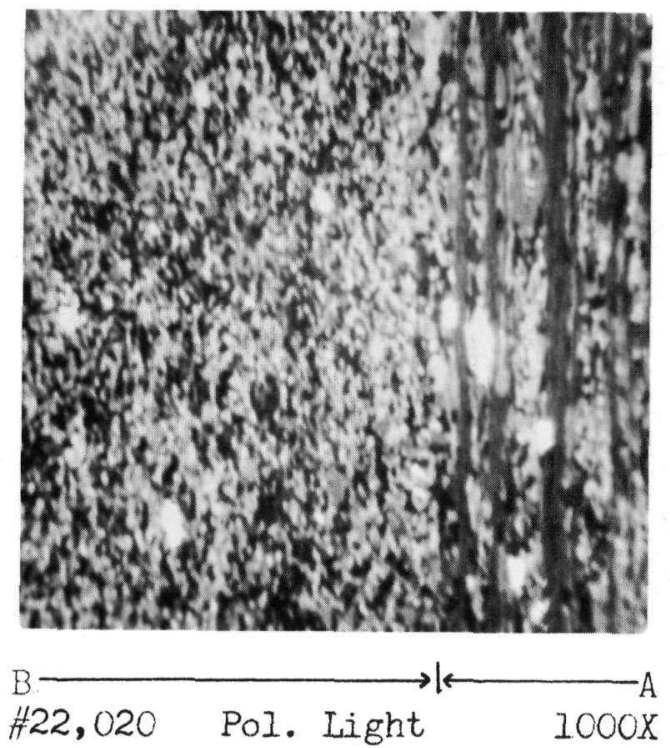

b. Annealed 400 hours at $320^{\circ} \mathrm{C}$

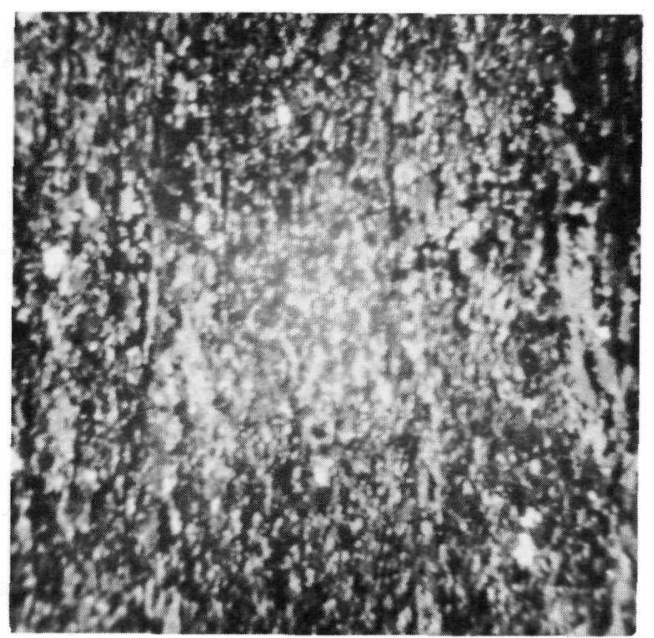

\#22,016 Pol. Light

$1000 \mathrm{X}$ c. Annealed 5 minutes at $400^{\circ} \mathrm{C}$

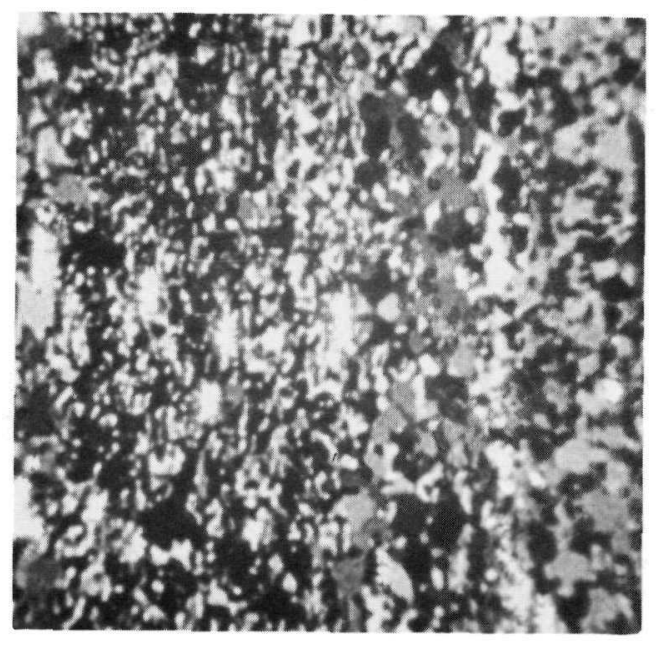

$\# 21,380$
Pol. Light

$1200 X$ d. Annealed 15 hours at $400^{\circ} \mathrm{C}$

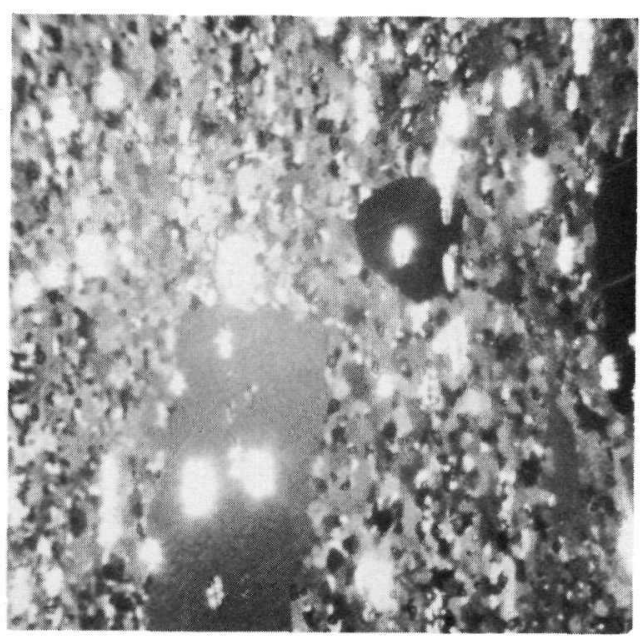

$\# 22,014$

Pol. Light

$1000 \mathrm{X}$ 
Figure 16. Recrystallization Behavior of Lightly Deformed Areas in H.P Specimens.

a. Annealed 42 hours at $360^{\circ} \mathrm{C}$ ( $74 \%$ recrystallized)
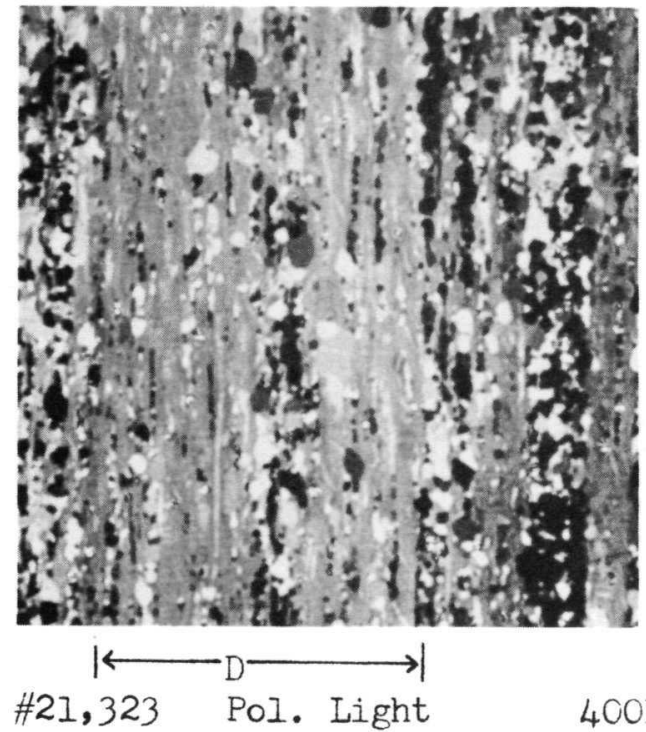

$400 X$
c. Annealed 92 hours at $360^{\circ} \mathrm{C}$ (74\% recrystallized)
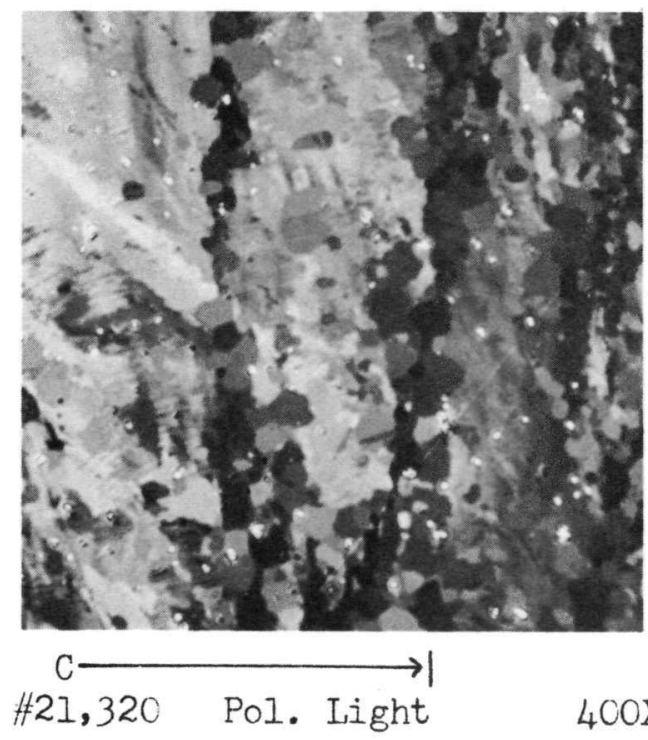

$400 X$

b. Annealed 42 hours at $360^{\circ} \mathrm{C}$ (74\% recrystallized)

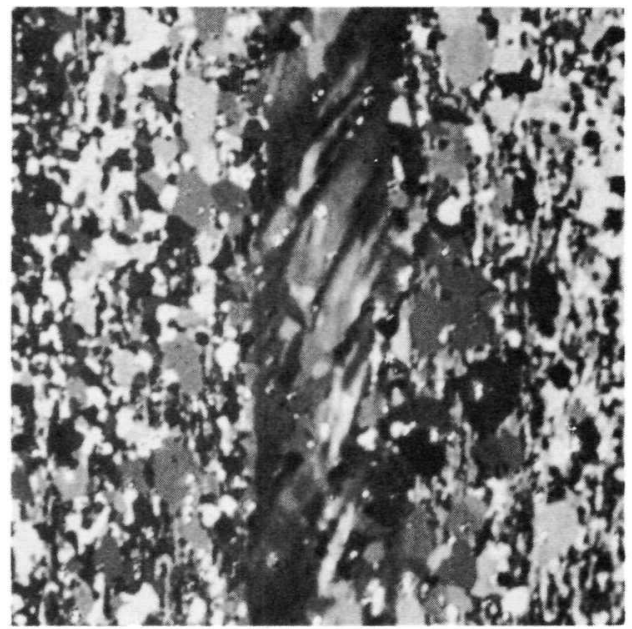

$$
\leftarrow \leftarrow \mathrm{C} \longrightarrow \mid
$$

\$21,317 Pol. Light

$400 X$ d. Annealed 5 minutes at $400^{\circ} \mathrm{C}$ (82\% recrystallized)
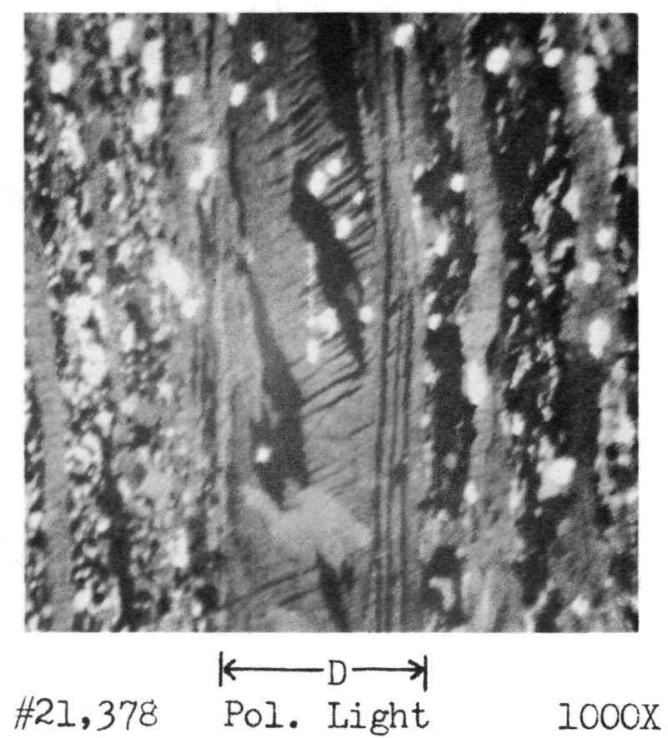
Because of the extreme heterogeneity of deformation in these materials, the final recrystallized grain size was not uniform in a particular specimen; however, data for average grain size did yield some interesting results (Table VI). As would be expected, specimens annealed for long times at low temperatures had rather small grain sizes and those annealed at high temperature gave larger grains. It is interesting to note that specimens annealed at $360^{\circ}$ and $400^{\circ} \mathrm{C}$ to comparable percent recrystallization had approximately the same recrystallized grain size.

\section{TABLE VI}

Average Grain Size, Volume Percent Recrystallization and Change in Mean Expansion Coefficient for Selected HP-2 Specimens

\begin{tabular}{|c|c|c|c|c|}
\hline \multicolumn{2}{|c|}{$\begin{array}{c}\text { Annealing Treatment } \\
\left({ }^{\circ} \mathrm{C}\right)\end{array}$} & $\begin{array}{c}\text { Average Grain } \\
\text { Size (mm) }\end{array}$ & $\begin{array}{c}\text { Volume Percent } \\
\text { Recrystallized }\end{array}$ & $\begin{array}{c}\text { Change in Mean } \\
\text { Expansion } \\
\text { Coefficient } \\
\text { (hours) }\end{array}$ \\
\hline 320 & 200 & 0.0007 & 72 & 0.43 \\
360 & 200 & 0.0043 & 98 & 1.53 \\
400 & 1 & 0.0035 & 91 & 3.81 \\
400 & 15 & 0.0049 & 99 & 5.84 \\
650 & 48 & 2.5 & 100 & 6.89 \\
\hline
\end{tabular}

Figure 17 illustrates the behavior of a lightly deformed area in a specimen annealed for 15 hours at $380^{\circ} \mathrm{C}$. The portion outlined in Figure 17 a probably represents a single grain prior to fabrication at room temperature. Many recrystallized grains are present at the tips of the elliptically shaped area. The non-recrystallized portion was divided into three parts (labeled 1, 2 and 3 in Figures 17a and 17b) by bands of fine grains. Area 1 was separated from area 3 by a rather obvious band, one grain wide. The boundary between areas 1 and 2 was also a band of recrystallized grains, as shown in Figure 17b. Within areas 1 and 3 faint lines, labeled $\mathrm{T}$, were parallel to the common boundary; these appear to be twins. No twins can be seen parallel to the boundary between 1 and 2; however, it is concluded that both of the boundary grain bands were formed by the recrystallization of twinned material. The number of grains was increased at the junction of the two boundaries; also, the recrystallized material surrounding areas 1,2 and 3 arranged was geometrically in a manner similar to that between the boundary bands. It seems likely, then, that the intersecting points of twins and the twins themselves serve as preferential sites for recrystallization.

Another metallographic observation pertinent to the annealing of HP material is illustrated in Figure 18, where typical structures of specimens annealed for 48 hours at $650^{\circ} \mathrm{C}$ are shown. The macroetched 
Figure 17. Recrystallization Behavior of a Lightly Deformed Area in a. HP Specimen Annealed 15 Hours at $380^{\circ} \mathrm{C}$ (Rolling direction horizontal - 83\% recrystallized).

a.

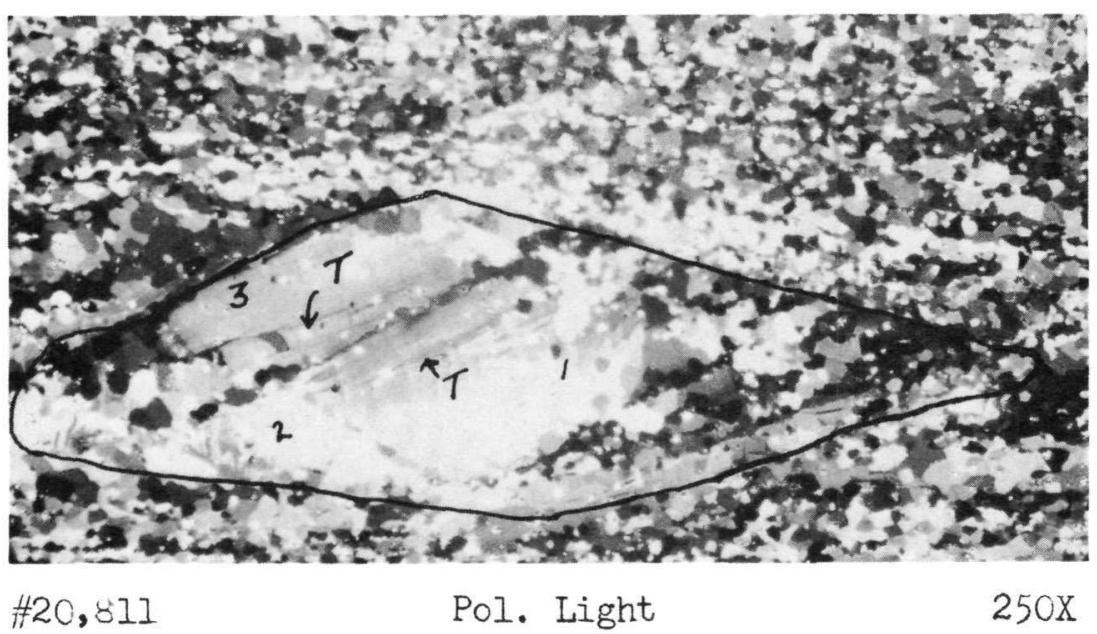

b. Vietallographic stage rotated $67^{\circ}$ from a.

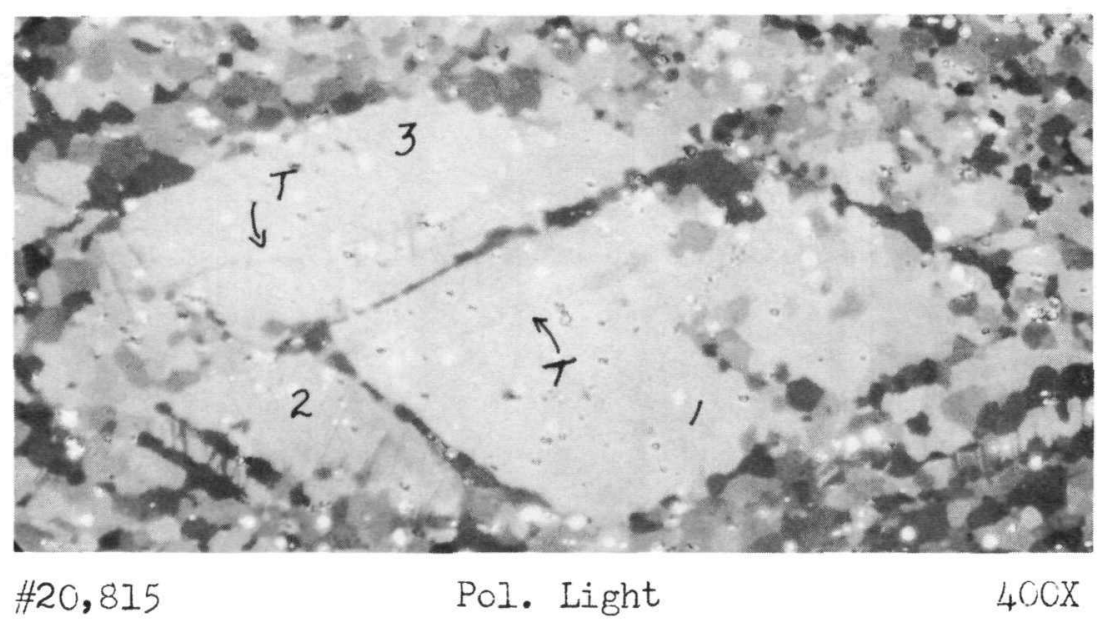


Figure 18. Grain Coarsening in a HP-2 Specimen Annealed 200 Hours at $320^{\circ} \mathrm{C}$ and Reannealed 48 Hours at $650^{\circ} \mathrm{C}$.

a. Photograph of macroetched specimen

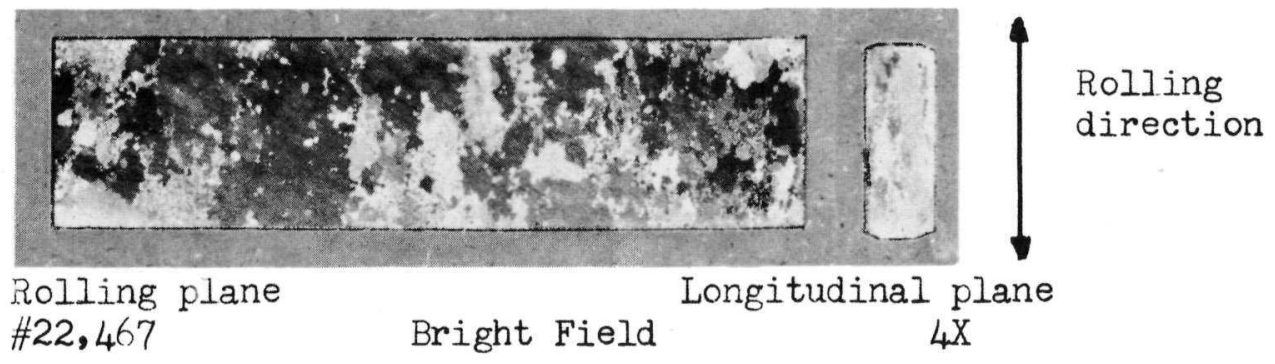

b. Partially coarsened area in rolling plane.

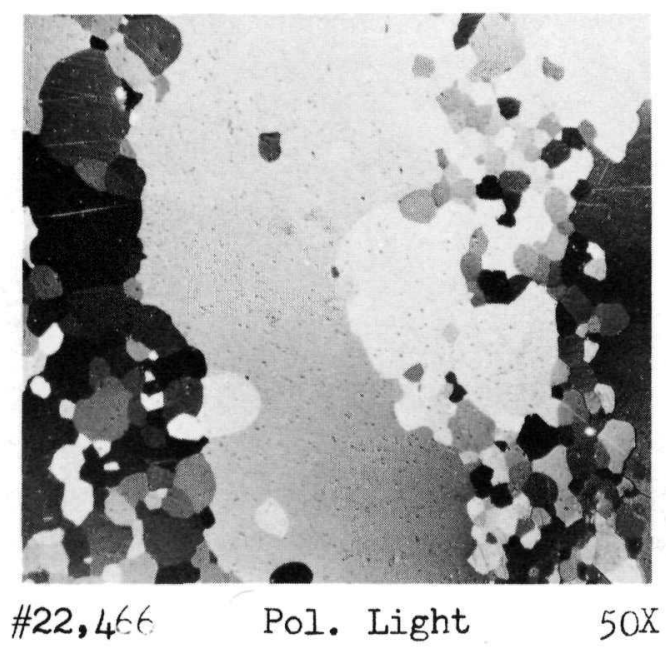
c. Uncoarsened area in rolling plane.

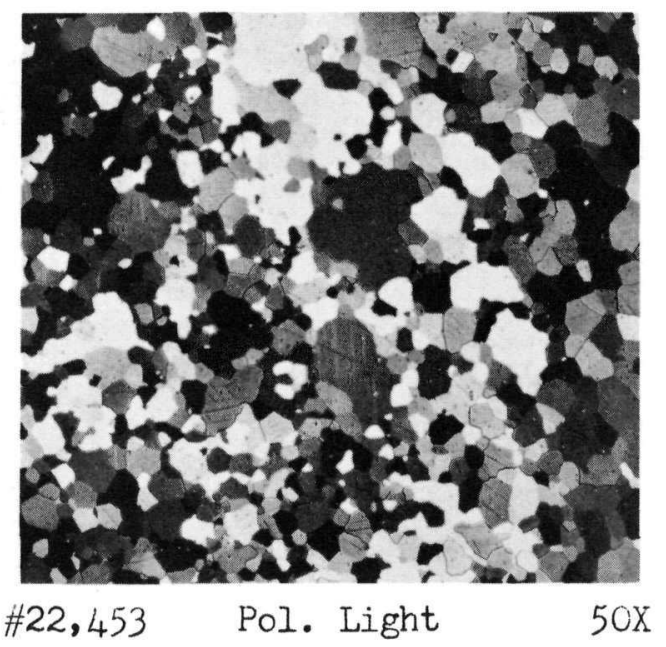


dilatometer specimen in Figure $18 \mathrm{a}$ clearly indicates that it has undergone partial grain coarsening. Figure $18 \mathrm{~b}$ and $18 \mathrm{c}$ show, respectively, a partially coarsened area and an uncoarsened area.

4. Structures of sheet $\mathrm{N}$ specimens: As was indicated above, the sheet $\mathrm{N}$ material yielded metallographic observations very similar to those for the HP specimens. The primary differences between the two types of materials were the rates of the recrystallization processes. Typical structures of sheet $\mathrm{N}$ specimens are shown in Figures 19 and 20.

Structures of zones B and C in the as-rolled condition are illustrated in Figure 19. Sheet $\mathrm{N}$ contained $45 \%$ by volume zone A, $20 \%$ zone $\mathrm{B}, 24 \%$ zone $\mathrm{C}$, and $11 \%$ zone $\mathrm{D}$ in the as-rolled condition. The similarity in behavior of these zones in sheet $\mathrm{N}$ material, upon annealing, to that observed for the HP specimens is illustrated in Figure 20. Partial recrystallization to very fine grains in zone A occurred after annealing for 15 hours at $360^{\circ} \mathrm{C}$ (Figure 20a). Annealing for 200 hours at $360^{\circ} \mathrm{C}$ (Figure 20b) caused nearly complete recrystallization of the A and B zones to very fine recrystallized grains, with some of these being absorbed by larger grains. Figure $20 \mathrm{c}$ shows similar behavior for a specimen annealed for 15 hours at $400^{\circ} \mathrm{C}$. In this case, the absorbing grains are somewhat larger than those of Figure 20b. Finally, Figure 20d shows a D zone in a specimen annealed for 92 hours at $400^{\circ} \mathrm{C}$. Recrystallization has not been completed, but it has recovered sufficiently to yield subgrained areas.

Figure 19. Microstructures of As-rolled Sheet N Specimen.

$$
\text { a. B type zone }
$$

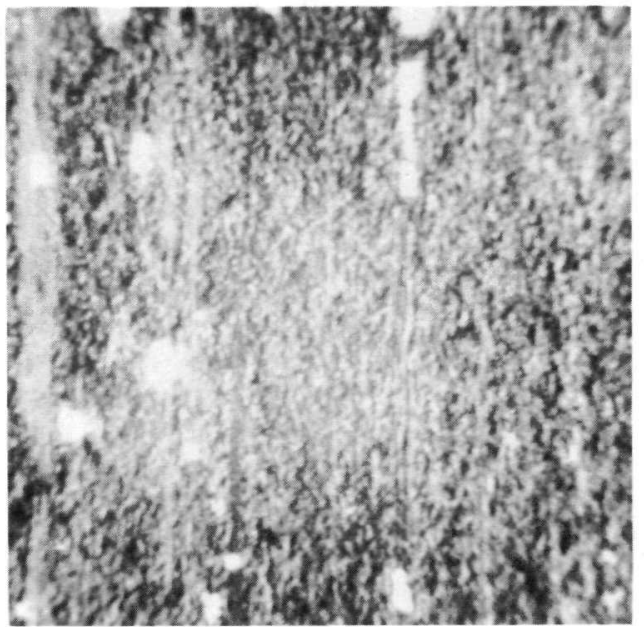

\#22,015 Pol. Light 1000X b. C type zone

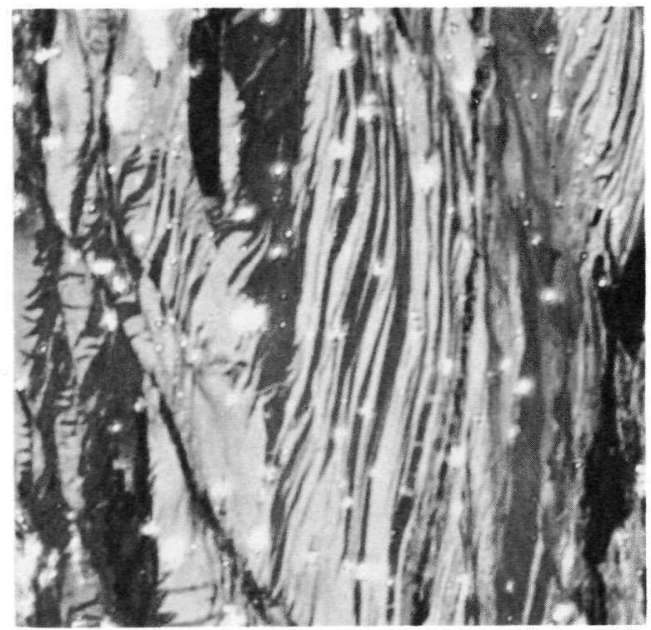

\#22,152 Pol. Light 400X 
Figure 20. Microstructures of Annealed Sheet iv Specimens.

a. Annealed 15 hours at $360^{\circ} \mathrm{C}$ (10\% recrystallized)

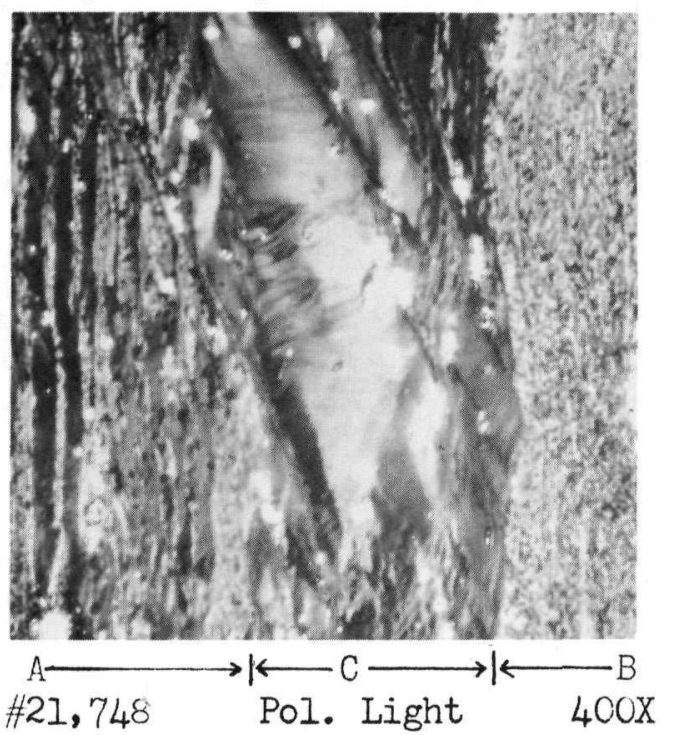

c. Annealed 15 hours at $400^{\circ} \mathrm{C}$ ( $84 \%$ recrystallized)

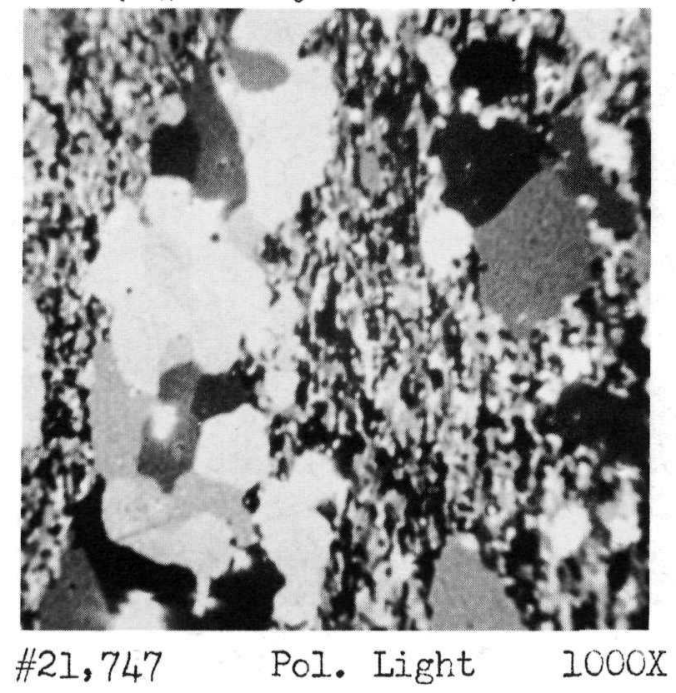

b. Annealed 200 hours at $360^{\circ} \mathrm{C}$ (65\% recrystallized)

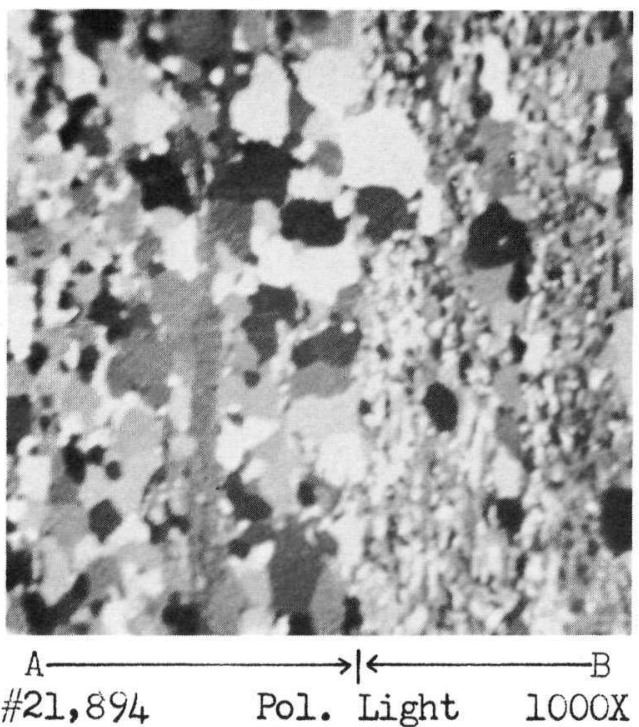

d. Annealed 92 hours at $400^{\circ} \mathrm{C}$ (99\% recrystallized)

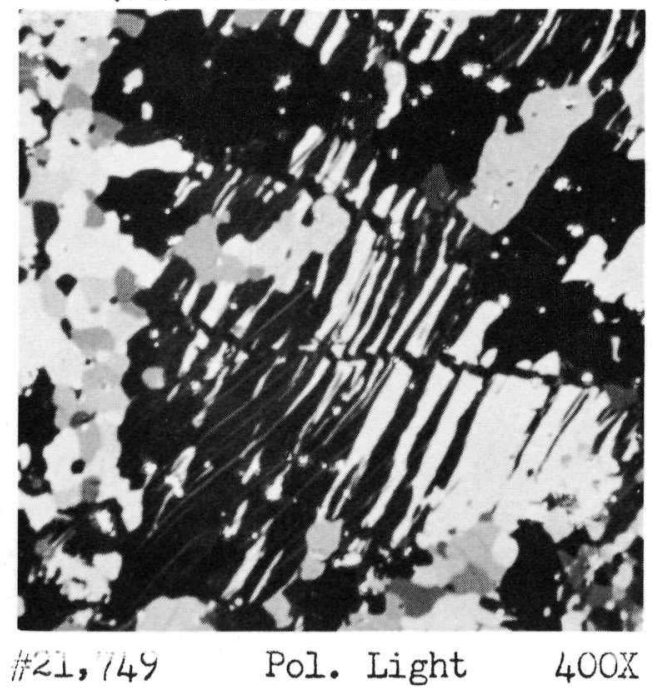


IV. DISCUSSION

A. Effect of Annealing upon Preferred Orientation Changes

As indicated previously, Cabane and Petit(1) concluded from their work that uranium sheet heavily rolled at room temperature can be recrystallized in the temperature range from $320^{\circ}$ to $420^{\circ} \mathrm{C}$ without change in preferred orientation. Annealing at higher temperatures caused a second recrystallization and an accompanying change in preferred orientation. Since that time, Cabane and Blanchon(6) have performed experiments, similar to the original ones, on French uranium of current purity and high-purity uranium (HPX-16) furnished by ANL, but they failed to confirm the previous observations.

On the other hand, the present work, also performed on HPX-16 material, tended to confirm the original observations of Cabane and Petit. The results clearly show that recrystallization to an extent as high as $98 \%$ can be obtained by long-time anneals at $360^{\circ} \mathrm{C}$ with essentially no change in expansion coefficient; whereas, if the material is annealed to comparable recrystallization at $400^{\circ} \mathrm{C}$, an appreciable change in expansion coefficient may be observed. In addition, it has been demonstrated that anneals at high temperatures in the alpha phase are accompanied by a second change in expansion coefficient and that there is metallographic evidence of grain coarsening. The present work suffers in that preferred orientations were not determined directly: rather, thermal expansion was used to give an indirect measurement. Indeed, it was impossible to obtain any measurements of preferred orientation because of the large grain size prior to final fabrication and, therefore, the inability to obtain statistically valid X-raydata.

The failure of Cabane and Blanchon to observe recrystallization without change in preferred orientation at the lower temperatures can be attributed to the fact that their annealing times were relatively short ( 2 and 24 hours). In the present work, times of 92 hours, or greater, were required before appreciable recrystallization was found at $360^{\circ} \mathrm{C}$. Corres pondingly longer times were required for annealing at lower temperatures, whereas only 15 hours was required at $400^{\circ} \mathrm{C}$.

The factors which control the recrystallization at lower temperatures of uranium heavily rolled at room temperature without a preferred orientation change are not understood. The microstructural features do not correlate directly with this phenomenon. For example, it is not associated with the presence of very fine recrystallized grains. Eighty-five percent recrystallization can be obtained at $400^{\circ} \mathrm{C}$ with only a small change in expansion coefficient (Table V). Appreciable amounts of very fine-grained material were found in this condition. Upon further recrystallization the expansion coefficient increased greatly and the microstructures showed the amounts of very fine grains to be decreasing 
rapidly. On the other hand, the amount of very fine-grained material decreased to zero upon annealing for 200 hours at $360^{\circ} \mathrm{C}$, and the expansion coefficient was essentially unchanged. In addition, the differences in preferred orientation of almost fully recrystallized specimens annealed at $360^{\circ}$ and $400^{\circ} \mathrm{C}$ cannot be ascribed to differences in grain size as shown in Table VI. A specimen annealed for 15 hours at $400^{\circ} \mathrm{C}$ had an average grain diameter of $0.0049 \mathrm{~mm}$ and a change in mean expansion coefficient of $5.84 \times 10^{-6}$ per ${ }^{\circ} \mathrm{C}$, whereas annealing for 200 hours at $360^{\circ} \mathrm{C}$ to a comparable recrystallization yielded a similar average grain diameter of $0.0043 \mathrm{~mm}$ but only had change in expansion coefficient of $1.53 \times 10^{-6}$ per ${ }^{\circ} \mathrm{C}$. In addition, a specimen annealed for 1 hour at $400^{\circ} \mathrm{C}$ had a smaller average grain diameter than one annealed at $360^{\circ} \mathrm{C}$ but a larger change expansion coefficient.

Retention of as-rolled preferred orientation components upon "recrystallization" have been explained as subgrain growth by Semchyshen and Timmons(7) for molybdenum sheet and by Beck and $\mathrm{Hu}(8)$ and Beck(9) for aluminum. As the subgrains progressively increase in size, the disorientation between neighbors becomes greater: and the microstructural characteristics approaches that expected for a material undergoing primary recrystallization; that is, subgrain growth appears to transform gradually to ordinary grain growth with no precise separation of the processes. The microstructural observations of the present work do not agree with such an explanation for, in all cases, the final stages of recrystallization were accompanied by discontinuous growth of grains with orientations distinctly different from those of the material from which they grew。

The differences in preferred orientations resulting from recrystallization at low and high temperatures in the present work may be attributed to variations in preferential grain growth. Specimens annealed at $400^{\circ} \mathrm{C}$ appeared to have more preferential grain growth than those annealed at $360^{\circ} \mathrm{C}$ in that the former showed more areas of low contrast. Additional support of this viewpoint lies in the fact that a specimen annealed at $360^{\circ} \mathrm{C}$ to $98 \%$ recrystallization and reannealed at $400^{\circ} \mathrm{C}$ did not show a change in the mean expansion coefficient; whereas one annealed to $85 \%$ recrystallization at $320^{\circ} \mathrm{C}$ and reannealed at $400^{\circ} \mathrm{C}$ did have a change (Table IV). The former sample demonstrates that the recrystallized:structure and preferred orientation established at $360^{\circ} \mathrm{C}$ are fixed and cannot be changed by reannealing at $400^{\circ} \mathrm{C}$. On the other hand, the latter specimen has $70 \%$ very fine recrystallized grains plus some unrecrystallized material. Reannealing at $400^{\circ} \mathrm{C}$ apparently permitted preferential grain growth in the very fine grains and in the unrecrystallized material to establish a different preferred orientation. These behaviors, however, do not define the factors which control recrystallization without preferred orientation change at the low temperatures. 


\section{B. Effect of Annealing upon Microstructure}

The microstructures of the sheets heavily rolled at room temperature can be separated into the two main categories: one of the heavily deformed areas and a second of lightly deformed areas. In general, the latter areas constituted the minor fraction and showed evidence of recovery by polygonization, followed by normal recrystallization after long times at low temperatures or shorter time intervals at higher temperatures. Heavily deformed areas were characterized by recrystallization, first, to very fine grains, followed by the formation of larger grains which appeared to be growing at the expense of the finer grains.

Zone B portions of the deformed structures appeared similar to the "speckled" areas observed by Cabane and Petit(1) and by Madsen.(10) Early recrystallization in these and zone A materials yielded structures which had the same peppery, dot-like appearance. Madsen reported that the "speckled" areas occupied between 12 to $25 \%$ of the as-rolled structure, while Cabane and Petit gave figures ranging from 10 to $30 \%$. These values agreed well with those found in the present work (Table V). Cabane and Petit postulated that these areas originated from grains oriented so as not to deform by twinning, but only by slip and kinking. Madsen, on the other hand, demonstrated that such areas, in materials reduced to $40 \%$ in thickness, arose from grains where kink bands intersected twins at a very oblique angle.

Cabane and Petit's observations of the "speckled" areas during annealing can be summarized as follows. Heating for 40 hours at $320^{\circ} \mathrm{C}$ brought about coarsening; for this reason they referred to the areas as "polygonized cells." After 40 hours at $360^{\circ} \mathrm{C}$ some non-contrasting crystals rapidly "absorb the polygonized cells" and this "discontinuous" growth was accompanied by considerable decrease in microhardness. The amount of non-contrasting bands reached $80 \%$ by volume after annealing for 40 hours at $390^{\circ} \mathrm{C}$. After annealing at $420^{\circ} \mathrm{C}$, the proportion of non-contrasting crystals fell to $10 \%$. The term "non-contrasting" is somewhat confusing because in the present work distinct contrast was observed at all times in the "speckled" areas. Madsen observed that coarsening was not always apparent in "speckled" areas before new grains grew, and their proportion did not increase during recrystallization. Since $400^{\circ} \mathrm{C}$ was the lowest annealing temperature, he could easily have missed the early stages where Cabane and Petit and the present authors observed the amount of this material to increase.

The "speckled" areas were followed carefully throughout this investigation; their quantities found in the as-rolled material and various annealed specimen are tabulated in Table V. As was indicated above, the "speckled" material of annealed specimens in the present work have as their origin zones $\mathrm{A}$ and $\mathrm{B}$ deformed materials, which constituted the 
major portion of the as-rolled structures. Upon annealing, the crystallites in zone B areas increased gradually in contrast and size until they attained sufficient magnitude to be resolved at magnifications of $1000 \mathrm{X}$ to $1300 \mathrm{X}$, where they are considered as very fine recrystallized grains. In zone A areas the fine grains developed in narrow rows separating deformed material. The latter accounts for the increased quantities of "speckled" material found in specimens annealed at low temperature over that observed in the as $\sim$ rolled condition.

It may well be that the "speckled" areas in annealed samples are the result of polygonization and subgrain growth, as is considered to be the case by Cabane and Petit. Such an explanation appears to apply to the very fine grains found in recrystallized zone B areas; however, it is difficult to understand why they have as much contrast as they do. On the other hand, Madsen's proposal that the "speckled" areas arise from very oblique twin and kink band intersections appears to be more plausible. It is known that such heavily strained portions are preferential sites for recrystallization. In the present work the zone $B$ areas were the first to recrystallize, with zone A following shortly thereafter. In the latter case, the first very fine grains formed were found in bands separating deformed material. As the annealing progressed the quantity of fine grains increased and the amount of deformed material decreased. The very fine grains thus formed showed rather high contrast, as did the fine grains formed in zone $B$ areas. Both of these structures showed as much contrast as did the larger grains which ultimately absorbed them. Such distinct contrasts would not be expected if the structures were formed by processes of polygonization and subgrain growth. In any event, the processes which form the annealed "speckled" areas are not important in fully recrystallized material, because the final grains in these areas were formed by discontinuous growth of somewhat larger grains at the expense of the very fine recrystallized grains.

\section{$\mathrm{V} \cdot$ CONCLUSIONS}

The present work indicates that three recrystallized preferred orientations can be obtained for high-purity uranium sheet heavily rolled at room temperature, depending upon the annealing conditions. One recrystallized preferred orientation, which was essentially the same as that of the as-rolled material, resulted from annealing for long times at $360^{\circ} \mathrm{C}$ or lower temperatures. A second preferred orientation was created by annealing for moderate periods of time at temperatures between $400^{\circ}$ and $600^{\circ} \mathrm{C}$. A third preferred orientation accompanied grain coarsening at $650^{\circ} \mathrm{C}$.

The as $\rightarrow$ rolled microstructures observed in the present work were extremely. heterogeneous and consisted of four general types. Zone A had a complex appearance consisting of very heavily deformed, narrow bands. 
Zone B, also heavily deformed, had a "speckled" appearance. Zone C was only lightly deformed and consisted of narrow, bent bands with some evidence of kinking. Finally, zone D showed little deformed structure. The first two zones occupied the major portions of the structures.

Upon annealing, the heavily deformed areas first formed very fine recrystallized grains, which in the latter stages of recrystallization were absorbed by discontinuous growth of somewhat larger grains. Annealing of the lightly deformed areas was characterized by subgrain formation, followed by normal recrystallization. In general, these areas did not recrystallize until the processes in zones A and B were nearing completion.

The two fabrications of high-purity uranium from the same ingot showed some differences in behavior. The recrystallization rates of the sample rolled with the 9 in. diameter mill were significantly higher than those of the sample rolled on the $17 \mathrm{in}$. diameter mill, but the characteristics of their microstructures and expansion coefficients were about the same.

The French sheet $\mathrm{N}$ specimens gave metallographic results and expansion coefficients similar to those observed for the high-purity uranium; however, complete recrystallization at higher temperatures did not result in as large a change of mean expansion coefficient as was observed for high-purity uranium.

\section{FUTURE WORK}

The large grain size prior to final fabrication of the specimens employed in the present work prohibited quantitative measurements of preferred orientation by techniques such as those employed by Mueller, Knott and Beck.(11) Thus, precise measurements of preferred orientation were not made and dilatometry was resorted to as a qualitative measure of change in preferred orientation. For a quantitative determination of the preferred orientation a starting material of relatively small uniform grain size is needed. Fisher $(12)$ has demonstrated that such structures can be obtained by a step-reduction and annealing procedure. A future study is to be carried out on material treated in this manner prior to the $80 \%$ reduction at room temperature. Complete measurements of the characteristics of thermal expansion and preferred orientations will be coupled with detailed metallographic observations. 
VII. ACKNOWLEDGMENT

The authors are indebted to Drs. F. G. Foote and H. H. Chiswik, under whose direction the present work was performed. We would also like to thank Professor G. Cabane of the Nuclear Studies Center at Saclay for arranging for the transmittal of the French sheet $\mathrm{N}$ sample to us.

\section{REFERENCES}

1. Cabane, G. and Petit, J., "Study of the Annealing of Rolled Uranium," Rev. met. 51 603-613 (1954).

2. Lloyd, L. T., "Recording Quartz Differential Dilatometer, "ANL-5372.

3. Smith, C. S. and Suttman, L., "Measurement of Internal Boundaries in Three Dimensional Structures by Random Sectioning, "Trans. AIME 197 $81-87$ (1953).

4. Lloyd, L. T. and Chiswik, H. H., "Deformation Mechanisms of AlphaUranium Single Crystals, "Trans. AIME 203 1206-1214 (1955).

5. Madsen, P。E., "Some Preliminary Observations on Recovery Recrystallization and Grain Growth in Alpha Uranium,"A.E.R.E。-M/R-1509 (September 1954)。

6. Cabane, G. and Blanchon, K. A. "The Influence of Purity on Recrystallization and Texture Change of Uranium Sheets," MCA/388 (February 1957).

7. Semchyshen, M. and Timmons, G. A., "Preferred Orientation of ArcCast Molybdenum Sheet, "Trans. AIME 194 279-286 (1952)。

8. Beck, P. A。 and Hu, H., "Annealing Textures in Rolled Face $\mathrm{H}_{\text {Centered }}$ Cubic Metals ${ }^{" ~ T r a n s . ~ A I M E ~} 194$ 83-90 (1952).

9. Beck, P.A. "Annealing of Cold Worked Metals," Advances in Physics 3 $245-324(1954)$.

10. Madsen, P.E., "The Recrystallization of Rolled Uranium Sheet, A.E.R.E。 $\mathrm{M} / \mathrm{R}-1721$ (August 9, 1955).

11. Mueller, M. H., Knott, H. W. and Beck, P.A., "Preferred Orientation in $300^{\circ} \mathrm{C}$ Rolled and Recrystallized Uranium Sheet " ANL-5117 (September 1953).

12. Fisher, E. S., "Preparation of Alpha-Uranium Single Crystals by a Grain-Coarsening Method," Trans.AIME 209882 (1957). 